\title{
Estimation of dynastic life-cycle discrete choice models
}

\author{
George-Levi Gayle
}

Department of Economics, Washington University in St. Louis and Federal Reserve Bank of St. Louis

\section{LIMOR GOLAN}

Department of Economics, Washington University in St. Louis and Federal Reserve Bank of St. Louis

\section{Mehmet A. Soytas}

Graduate School of Business, Ozyegin University

\begin{abstract}
This paper explores the estimation of a class of life-cycle discrete choice dynastic models. It provides a new representation of the value function for these class of models. It compare a multistage conditional choice probability (CCP) estimator based on the new value function representation with a modified version of the full solution maximum likelihood estimator (MLE) in a Monte Carlo study. The modified CCP estimator performs comparably to the MLE in a finite sample but greatly reduces the computational cost. Using the proposed estimator, we estimate a dynastic model and use the estimated model to conduct counterfactual simulations to investigate the role Nature versus Nurture in intergenerational mobility. We find that Nature accounts for 20 percent of the observed intergenerational immobility at the bottom of income distribution. That means that 80 percent of mobility at the bottom of the income distribution is explained by economic decision and economic/institutional constraints.
\end{abstract}

KEYwords. Discrete choice models, dynastic models, intergenerational mobility, nature versus nurture.

JEL CLASSIFICATION. C13, J13, J22, J62.

\section{INTRODUCTION}

The importance of parents' altruism toward their children and children's altruism toward their parents has long been recognized as an important factor underlying the economic behavior of individuals. Economic models that incorporate these intergenerational links are normally referred to as dynastic models. Many important economic

George-Levi Gayle: ggayle@wustl. edu

Limor Golan: lgolan@wustl . edu

Mehmet A. Soytas: mehmet . soytas@ozyegin.edu.tr

We thank the participants of 3rd Annual All Istanbul Meeting, Sabanci University 2013; Society of Labor Economists Annual Meetings 2015; European Economic Association 30th Annual Congress 2015; Econometric Society (11th) World Congress 2015; Southern Economic Association 85th Annual Meetings 2015; 10th International Conference on Computational and Financial Econometrics 2016; and the seminar participants at Izmir University of Economics, TOBB University of Economics and Technology, and Marmara University. The views expressed are those of the individual authors and do not necessarily reflect official positions of the Federal Reserve Bank of St. Louis, the Federal Reserve System, or the Board of Governors.

(C) 2018 The Authors. Licensed under the Creative Commons Attribution-NonCommercial License 4.0. Available at http://qeconomics.org. https:// doi.org/10.3982/QE771 
behaviors-and hence the welfare effect of many public policies—critically depend on whether these dynastic links are explicitly modeled.

Several papers have documented that (i) the distribution of wealth is more concentrated than that of labor earnings and (ii) it is characterized by a smaller of fraction of households owning a larger fraction of total wealth over time. There are different models of dynastic transfers explaining the persistence in wealth and income across generations (e.g., the Loury (1981), model of transmission of human capital and the Laitner (1992), model of bequests); however, in these models fertility is exogenous. Barro and Becker (1988, 1989) develop dynastic models with endogenous fertility; however, in their models endogenizing fertility leads to a lack of persistence in earnings and wealth because wealthier households have more children and therefore dynastic transfers do not depend on wealth and income. The data clearly show persistence in income across generations. Subsequently, dynastic models with endogenous fertility that capture the dynastic persistence of income and wealth have been analyzed extensively, but such models have not been estimated mainly because of computational feasibility considerations. This paper develops an estimator for dynastic models of dynastic transfers and estimates a model quantifying the different factors generating the persistence of income.

Alvarez (1999) combined the main features of the above-mentioned models by incorporating the fertility decision into the Laitner (1992) and Loury (1981) dynastic transfer models. While some models, as Laitner (1992), incorporated an elaborate finite life-cycle model for adults in each generation, in other models there is one period of childhood and one period of adulthood. The framework we study incorporates all these elements and develops a model in which altruistic parents make discrete choices of birth, labor supply, and discrete and continuous investment choices in children. In particular, in order to accommodate many models in the literature, parents choose time with children and a continuous monetary investment in their children every year over their life cycle. The model can also be extended to include bequests. The model is a partial equilibrium model, and as in most dynastic models and in the basic setup, there is one decision-maker in a household; however, we show that it can be easily extended to a unitary household. ${ }^{1}$

While the study of dynastic models has been widespread in the economic literature, these studies have been largely theoretical or quantitative theory. However, the estimation of these models and the use of these estimated models to conduct counterfactual policy analysis are nonexistent. There are two main reasons for this gap; the first is data limitation and the second is computational feasibility. Ideally, one would need data on the choices and characteristics of multiple generations linked across time to estimate these dynastic models. The number of generations needed for estimation can be reduced to two by analyzing the stationary equilibrium properties of these model. Recently, data on the choices and characteristics of at least two generations have become available in the National Longitudinal Survey of Youth (NLSY79), Panel Study of Income Dynamics (PSID), and a number of European administrative datasets.

\footnotetext{
${ }^{1}$ In a companion paper, we extend the current framework to incorporate nonunitary households (Gayle, Golan, and Soytas (2014)).
} 
There are two main estimators used in the literature to estimate dynamic discrete choice models: full solution method using the "nested fixed point" algorithm (NFXP) (see Wolpin (1984), Miller (1984), Pakes (1986), and Rust (1987) for early examples) and "conditional choice probability" (CCP) (see Hotz and Miller (1993), Altug and Miller (1998), and Aguirregabiria (1999)) estimators that do not require the solution to the fixed points. More recently, Aguirregabiria and Mira (2002) showed that an appropriately formed CCP-based estimator, "nested pseudo likelihood" (NPL), is asymptotically equivalent to an NFXP estimator. The major limitation of the NFXP estimation procedure is that it suffers from the curse of dimensionality (i.e., as the number of states in the state space increases, the number of computations increases at a rate faster than linear). Dynastic models add an additional loop to this estimation procedure: a nested fixed-point squared. Therefore, this estimation procedure suffers from the curse of dimensionality squared. However, even with a CCP estimator or an NPL estimator, estimation of the dynastic model requires dealing with further complications that are not present in single-agent dynamic discrete choice models.

The main difficulty is deriving the representation of the value functions of the problem. This difficulty is associated with the nonstandard nature of the problem. A dynastic model has finite number of periods in the life cycle in each generation and infinitely many generations are linked by the altruistic preferences. This framework does not fit into a finite horizon dynamic discrete choice model since in the last period, there is a continuation value associated with the next generation's problem that is linked to the current generation by the transfers and the discount factor. Therefore, we need to find a representation for the next generation's continuation value if we want to treat the problem as a standard finite-period problem and solve it by backward induction. ${ }^{2}$ In this paper, we propose a new estimation procedure based on a representation of the period value functions in terms of period primitives. In particular, we show that an appropriately defined alternative representation of the continuation value enables us to apply a CCP estimator to dynastic models. The general principles used in the estimation technique are well known in the literature, ${ }^{3}$ and hence the main contribution of this paper is showing how these principles can be combined to estimate dynastic models. In a Monte Carlo study, we demonstrate that a multistage CCP estimator based on the new value function representation have good small-sample properties that compare favorably to a full solution NFXP estimator. For this comparison, we use a pseudo maximum likelihood estimator (PML) so that our results would be more comparable to those of the NFXP maximum likelihood estimator.

We use the GMM version of the estimator developed in this paper to estimate a dynastic model of intergenerational transmission of human capital with unitary households. The estimated model captures well the labor supply, time with children, and fertility decisions of households. We then demonstrate the usefulness of our framework for

\footnotetext{
${ }^{2}$ Obviously, we can always solve the problem by NFXP if we assume that the problem is stationary in the generations. In this case, the solution to the dynamic programming problem requires solving the fixedpoint problem for the period value functions. However, as one can easily anticipate, we encounter the same computational burden of full solution. Therefore, our specific interest is CCP-type estimators.

${ }^{3}$ See Hotz and Miller (1993), Hotz, Miller, Sanders, and Smith (1994), Altug and Miller (1998), and Aguirregabiiria and Miria (2002) for the seminal contributions from which these general principles are derived.
} 
policy analysis. This is done by conducting counterfactual simulations to investigate the role of the automatic transmission of education across generation (Nature) on integenerational mobility at bottom of the income distribution. We find that without the Nature on the intergenerational education production function mobility at the bottom of the income distribution would have been 20 percent higher. That means that 80 percent of mobility at the bottom of the income distribution is explained by economic decision and economic/institutional constraints. Lastly, not accounting for the reoptimization of subsequent generations in the model, as is done in the approach outlined in this paper, will overstate the effect of Nature on mobility by between 20 and 90 percent.

Dynastic models have been used to study numerous topics in economics. These topics include explaining the cross-sectional correlation between parental wages and fertility (see Jones, Schoonbroodt, and Tertilt (2010), for a detailed overview of this literature), the relationship between inequality and growth (see, e.g., De la Croix and Doepke (2003)), the relationship between human capital formation and social mobility (see Heckman and Mosso (2014), for a survey of this literature), the relation among bequests, saving, and the distribution of wealth and earnings (see De Nardi (2004); Cagetti and De Nardi (2008), among others), ${ }^{4}$ and the optimality of different ways of funding social security. These models have been used to shed light on the effect of education, child care subsidies, child labor regulations, and wealth and income redistribution policies on individual welfare. Reviewing this vast and diverse literature is beyond the scope of this paper; however, a short review of two of the literature segments will suffice to illustrate the need to estimate these models, and hence the wide applicability of our estimation technique.

The first segment explains the widespread negative cross-sectional correlation between parental wage and fertility. The basic dynastic model as formulated by Barro and Becker (1989) cannot explain this negative correlation because wealthier parents increase the number of offspring, keeping transfer levels the same as less wealthy parents. Attempts in the literature to account for this negative correlation range from appropriately calibrating the model parameters so that the substitution effects are larger than the income effects, introducing the quality of children as a choice variable with an appropriate assumption about the cost of child-rearing (Becker and Lewis (1973), Becker and Tomes (1976), Moav (2005)), ${ }^{5}$ to introducing nonhomotheticity in preferences (see, e.g., Galor and Weil (2000), Greenwood and Seshadri (2002), or Fernandez, Guner, and Knowles (2005)). As summarized in Alvarez (1999), depending on the functional form assumptions of the primitives and values of the structural parameters, dynastic models could generate the negative correlation between parental wages and fertility. ${ }^{6}$ Therefore,

\footnotetext{
${ }^{4}$ For example, the De Nardi (2004) model explicitly focused on the transmission of physical and human capital from parents to children and intergenerational links. She shows that such a model can can induce savings behavior that generates a distribution of wealth that (i) is much more concentrated than that of labor earnings and (ii) also makes the rich keep large amounts of assets in old age to leave bequests to their descendants.

${ }^{5}$ See Jones, Schconbroodt, and Tertilt (2010, Section 5.2).

${ }^{6}$ Recently, Mookherjie, Prina, and Ray (2012) demonstrated that incorporating dynamic analysis of return to human capital can help explain the negative cross-sectional correlation between parental wages and fertility.
} 
whether the basic dynastic model can explain this negative cross-sectional correlation between parental wages and fertility is an empirical question requiring careful exploration of the source of identification and estimation (see Gayle, Golan, and Soytas (2014, 2015), for examples of these types of analysis).

The effects of the social security system on both capital accumulation and wealth distribution have been of great interest to economists and policy-makers for decades (see, for instance, Kotlikoff and Summers (1981), Caballé and Fuster (2003), among others). However, the optimal form of funding social security may depend on whether or not these intergenerational links are explicitly modeled. For example, Fuster, Imrohoroglu, and Imrohoroglu (2007) argued that when households insure members in the same family line, privatizing social security without compensation is favored by $52 \%$ of the population. If social security participants are fully compensated for their contributions and the transition to privatization is financed by a combination of debt and a consumption tax, 58\% experience a welfare gain. These gains and the resulting public support for social security reform depend critically on a flexible labor market. If the elasticity of the labor supply is low, then support for privatization disappears. Therefore, it is important to estimate these models because policy implications often depend on the value of key structural parameters. In Fuster, Imrohoroglu, and Imrohoroglu (2007), the key structural parameter was the elasticity of labor supply, but in other models it may be the altruism parameters themselves.

The rest of the paper is organized as follows. Section 2 presents the basic gender-less life-cycle dynastic model with only discrete choices. Section 3 presents the generic estimator of the life-cycle model and presents the Monte Carlo study. Section 4 extends the framework to include continuous choices and transfers, intra-household behaviors, and gender. Section 5 presents the basic framework of our empirical application. Section 6 presents our empirical results. Section 7 concludes, all proofs are provided in an appendix, and additional tables are provided in the Supplementary Material (Gayle, Golan, and Soytas (2018)).

\section{THEORETICAL FRAMEWORK}

The theoretical framework is developed to allow for estimation of a rich group of dynastic models and allows us to address many relevant policy questions. This section develops a model of altruistic parents who make transfers to their children. The transfers are discrete and can allow for (i) discrete time investment in children and (ii) monetary investment with discrete levels. Section 4 extends this basic framework to allow for continuous choices and transfers. This allows us to use the framework to analyze bequests or any continuous monetary transfers by parents to their children. We incorporate two important aspects of the problem. First, fertility is endogenous. Endogenous fertility has important implications for intergenerational transfers and the quantity-quality tradeoffs made by parents when they choose transfers as the well as number of offspring. Second, we include a life cycle for each generation. The life cycle is important to understanding fertility behavior, spacing of children, and the timing of different types of 
investments. This section analyzes a model with one gender-less decision-maker. We later extend this framework to a unitary household. ${ }^{7}$

We build on previous dynastic models that analyze transfers and intergenerational transmission of human capital. In some models, such as Loury (1981) and Becker and Tomes (1986), fertility is exogenous, whereas in others, such as Becker and Barro (1988) and Barro and Becker (1989), fertility is endogenous. The Barro-Becker framework is extended in our model by incorporating a life-cycle behavior model, based on previous work, such as Heckman, Hotz, and Walker (1985) and Hotz and Miller (1988), into an infinite-horizon model of dynasties. Our life-cycle model includes individuals choices about time allocation decisions, investments in children, and fertility. We formulate a partial equilibrium discrete choice model that incorporates life-cycle considerations of individuals from each generation into the larger framework. Adults in each generation derive utility from their own consumption, leisure, and the utility of their adult offspring. The utility of adult offspring is determined probabilistically by the educational outcome of childhood, which in turn is determined by parental time and monetary inputs during early childhood, parental characteristics (such as education), and luck. Parents make decisions in each period about fertility, labor supply, time spent with children, and monetary transfers. For simplicity, the only intergenerational transfers are transfers of human capital, as in Loury (1981). However, the framework can include any other choice of transfer that is discrete. We assume no borrowing or savings for simplicity. The model assumes that the educational outcome of children is revealed at the last period of parent's life cycle regardless of the birth date of the children. This assumption is similar to the Barro-Becker assumptions. In the parents' life cycle, adult children's behavior and choices do not affect the choices of parents. As in Barro-Becker, the choices can only be made by the children in their own life cycle which starts immediately after the parents' life cycle ends. ${ }^{8}$

In the model, adults live for $T$ periods. Each adult from generation $g \in\{0, \ldots, \infty\}$ makes discrete choices about labor supply $\left(h_{t}\right)$, time spent with children $\left(d_{t}\right)$, and birth $\left(b_{t}\right)$, in every period $t=1, \ldots, T$. For labor time, individuals choose no work, part-time, or full-time $\left(h_{t} \in(0,1,2)\right)$; for time spent with children individuals choose none, low, or high $\left(d_{t} \in(0,1,2)\right)$. The birth decision is binary $\left(b_{t} \in(0,1)\right)$. The individual does not make any choices during childhood, when $t=0$. All the discrete choices can be combined into one set of mutually exclusive discrete choice, represented as $k$, such that $k \in(0,1, \ldots, 17)$. Let $I_{k t}$ be an indicator for a particular choice $k$ at age $t ; I_{k t}$ takes the value 1 if the kth choice is chosen at age $t$ and 0 otherwise. These indicators are defined

\footnotetext{
${ }^{7}$ Treatment of households, with two decision-makers (with separate utility functions), marriage, and divorce, is involved and is beyond the scope of this paper. See Gayle, Golan, and Soytas (2014) for more details on one such model.

${ }^{8}$ In a model where adult children's behavior and choices do affect investment in children and fertility of the parents, solutions to the problems are significantly more complicated and it is not clear whether a solution exists.
} 
as follows:

$$
\begin{aligned}
I_{0 t} & =I\left\{h_{t}=0\right\} I\left\{d_{t}=0\right\} I\left\{b_{t}=0\right\}, \\
I_{1 t} & =I\left\{h_{t}=0\right\} I\left\{d_{t}=0\right\} I\left\{b_{t}=1\right\}, \\
I_{16 t} & =I\left\{h_{t}=1\right\} I\left\{d_{t}=2\right\} I\left\{b_{t}=1\right\}, \\
I_{17 t} & =I\left\{h_{t}=2\right\} I\left\{d_{t}=2\right\} I\left\{b_{t}=1\right\} .
\end{aligned}
$$

Since these indicators are mutually exclusive, then $\sum_{k=0}^{17} I_{k t}=1$. We define a vector, $x$, to include the time-invariant characteristics of the individual's education, skill, and race. Incorporating this vector, we further define the vector $z$ to include all past discrete choices as well as time-invariant characteristics, such that $z_{t}=\left(\left\{I_{k 1}\right\}_{k=0}^{17}, \ldots,\left\{I_{k t-1}\right\}_{k=0}^{17}\right.$, $x)$.

We assume the utility function is the same for adults in all generations. An individual receives utility from discrete choice and from consumption of a composite good, $c_{t}$. The utility from consumption and leisure is assumed to be additively separable because the discrete choice, $I_{k t}$, is a proxy for leisure and is additively separable from consumption. The utility from $I_{k t}$ is further decomposed into two additive components: a systematic component, denoted by $u_{1 k t}\left(z_{t}\right)$, and an idiosyncratic component, denoted by $\varepsilon_{k t}$. The systematic component associated with each discrete choice $k$ represents an individual's net instantaneous utility associated with the disutility from market work, the disutility/utility from parental time investment, and the disutility/utility from birth. The idiosyncratic component represents a preference shock associated with each discrete choice $k$ that is transitory in nature. To capture this feature of $\varepsilon_{k t}$, we assume that the vector $\left(\varepsilon_{0 t}, \ldots, \varepsilon_{17 t}\right)$ is independent and identically distributed across the population and time and is drawn from a population with a common distribution function, $F_{\varepsilon}\left(\varepsilon_{0 t}, \ldots, \varepsilon_{17 t}\right)$. The distribution function is assumed to be absolutely continuous with respect to the Lebesgue measure and has a continuously differentiable density.

Per-period utility from the composite consumption good is denoted $u_{2 t}\left(c_{t}, z_{t}\right)$. We assume that $u_{2 t}\left(c_{t}, z_{t}\right)$ is concave in $c$; that is, $\partial u_{2 t}\left(c_{t}, z_{t}\right) / \partial c_{t}>0$ and $\partial^{2} u_{2 t}\left(c_{t}, z_{t}\right) / \partial c_{t}^{2}<0$. Implicit in this specification is the inter-temporally separable utility from the consumption good, but not necessarily for the discrete choices, since $u_{2 t}$ is a function of $z_{t}$, which is itself a function of past discrete choices but is not a function of the lagged values of $c_{t}$.

Altruistic preferences are introduced under the same assumption as the BarroBecker model: Parents obtain utility from their adult offspring's expected lifetime utility. Two separable discount factors capture the altruistic component of the model. The first, $\beta$, is the standard rate of time preference parameter, and the second, $\lambda N^{-\nu}$, is the intergenerational discount factor, where $N$ is the number of offspring an individual has over her lifetime. Here, $\lambda(0<\lambda<1)$ should be understood as the individual's weighting of her offsprings' utility relative to her own utility. The individual discounts the utility of each additional child by a factor of $-\nu$, where $0<\nu<1$.

We let earnings $\left(w_{t}\right)$ be given by the earnings function $w_{t}\left(z_{t}, h_{t}\right)$, which depends on the individual's time-invariant characteristics, choices that affect human capital accumulated with work experience, and the current level of labor supply $\left(h_{t}\right)$. The choices 
and characteristics of parents are mapped onto their offspring's characteristics $\left(x^{\prime}\right)$ via a stochastic production function of several variables. The offspring's characteristics are affected by their parents' time-invariant characteristics, their parents' monetary and time investments, and the presence and timing of siblings. These variables are mapped into the child's skill and educational outcome by the function $M\left(x^{\prime} \mid z_{T+1}\right)$ where $z_{T+1}$ includes all parental choices and characteristics and contains information on the choices of time inputs and monetary inputs. Because $z_{T+1}$ also contains information on all birth decisions, it captures the number of siblings and their ages. We assume there are four mutually exclusive educational outcomes for offspring: less than high school (LH), high school (HS), some college (SC), and college (Coll). Therefore, $M\left(x^{\prime} \mid z_{T+1}\right)$ is a mapping of parental inputs and characteristics into a probability distribution over these four outcomes.

We normalize the price of consumption to 1 . Raising children requires parental time $\left(d_{t}\right)$ and market expenditure. The per-period cost of raising children is denoted $p c_{n t}$. Therefore, the per-period budget constraint is given by

$$
w_{t} \geq c_{t}+p c_{n t} .
$$

The sequence of optimal choice for both discrete choice and consumption is denoted as $I_{k t}^{o}$ and $c_{t}^{o}$, respectively. We can thus denote the expected lifetime utility at time $t=0$ of a person with characteristics $x$ in generation $g$, excluding the dynastic component, as

$$
U_{g T}(x)=E_{0}\left[\sum_{t=0}^{T} \beta^{t}\left[\sum_{k=0}^{17} I_{k t}^{o}\left\{u_{1 k t}\left(z_{t}\right)+\varepsilon_{k t}\right\}+u_{2 t}\left(c_{t}^{o}, z_{t}\right)\right] \mid x\right] .
$$

The total discounted expected lifetime utility of an adult in generation $g$ including the dynastic component is

$$
U_{g}(x)=U_{g T}(x)+\beta^{T} \lambda E_{0}\left[N^{-\nu} \sum_{n=1}^{N} U_{g+1, n}\left(x_{n}^{\prime}\right) \mid x\right],
$$

where $U_{g+1, n}\left(x_{n}^{\prime}\right)$ is the expected utility of child $n(n=1, \ldots, N)$ with characteristics $x_{n}^{\prime} \cdot{ }^{9}$ In this model, individuals are altruistic and derive utility from their offspring's utility, subject to discount factors $\beta$ and $\lambda N^{-\nu}$. ${ }^{10}$ This formulation is similar to the one in BarroBecker, but it is extended to allow for differences in gender and "types."

To simplify presentation of the model, we assume that $p c_{n t}$ is proportional to an individual's current earnings and the number of children, but we allow this proportion to depend on the state variables. This assumption allows us to capture the differential expenditures on children made by individuals with different incomes and characteristics.

\footnotetext{
${ }^{9}$ Note that this formulation can be written as an infinite discounted sum (over generations) of per-period utilities as in the Barro-Becker formulation.

${ }^{10}$ Note that since we add life-cycle, the regularity condition that implies that the discount factor of the children's utilities, $\beta^{T} \lambda N^{-\nu}$ is between zero and one is satisfied for any $N$, as $\beta$ is also between zero and one.
} 
Practically, this allows us to proxy for differences in social norms of child-rearing among different socioeconomic classes. ${ }^{11}$ Explicitly, we assume that

$$
p c_{n t}=\alpha_{N c}\left(z_{t}\right)\left(N_{t}+b_{t}\right) w_{t}\left(x, h_{t}\right)
$$

and, incorporating the assumption that individuals cannot borrow or save ${ }^{12}$ and equation (5), the budget constraint becomes

$$
w_{t}\left(x, h_{t}\right)=c_{t}+\alpha_{N c}\left(z_{t}\right)\left(N_{t}+b_{t}\right) w_{t}\left(x, h_{t}\right) .
$$

Solving for consumption from equation (6) and substituting for consumption in the utility equation, we can rewrite the third component of the per-period utility function, specified as $u_{2 k t}\left(z_{t}\right)$, as a function of just $z_{t}$ as follows:

$$
u_{2 k t}\left(z_{t}\right)=u_{t}\left[w_{t}\left(x, h_{t}\right)-\alpha_{N c}\left(z_{t}\right)\left(N_{t}+b_{t}\right) w_{t}\left(x, h_{t}\right), z_{t}\right] .
$$

Note that the discrete choices now map into different levels of utility from consumption. Therefore, we can eliminate the consumption decision as a choice and write the systematic contemporary utility associated with each discrete choice $k$ as ${ }^{13}$

$$
u_{k t}\left(z_{t}\right)=u_{1 k t}\left(z_{t}\right)+u_{2 k t}\left(z_{t}\right) .
$$

Incorporating the budget constraint manipulation, we can rewrite equation (3) as

$$
U_{g T}(x)=E_{0}\left[\sum_{t=0}^{T} \beta^{t} \sum_{k=0}^{17} I_{k t}^{o}\left[u_{k t}\left(z_{t}\right)+\varepsilon_{k t}\right] \mid x\right] .
$$

Alvarez (1999) theoretically analyzed and generalized the conditions under which dynastic models with endogenous fertility lead to intergenerational persistence in income and wealth. Following his analysis, we show empirically which assumptions are relaxed in our model and lead to persistence in income. The first is constant cost per child. In our model, the per-period costs of raising a child and transferring human capital is the cost described in equations (5) and (6), as well as the opportunity cost of time investment in children. Time investment in children and labor market time are modeled as discrete choice with three levels. This introduces nonlinearity. Even if we were able to capture the proportional increase in time with children as the number of children increases, the nonlinearity in labor supply decisions implies that the opportunity cost of time investment in children is not linear. Thus, the cost of transfer of human capital per

\footnotetext{
${ }^{11}$ In general, individuals can choose expenditures on children, but we do not observe spending in the data used for estimation in the empirical application.

${ }^{12}$ This assumption is not important for any of the results obtained in this paper. However, it simplifies the presentation by allowing all choices to be discrete. See Section 4 for a relaxation of this assumption.

${ }^{13}$ In our formulation, utility from consumption and leisure is assumed to be additively separable, and hence $u_{1 k t}\left(z_{t}\right)+\varepsilon_{k t}$ captures the utility of leisure corresponding to the choices of labor supply, time spent with children $\left(d_{t}\right)$, and the birth decision $\left(b_{t}\right)$ associated with choice $k$ in period $t$. In the empirical implementation, we ensure that the highest levels of labor supply and time with children are feasible by ensuring that they satisfy a time allocation budget constraint.
} 
child is not constant. Furthermore, in contrast to standard dynastic models and those analyzed in Alvarez (1999), we incorporate dynamic elements of the life cycle that involve age and experience effect. The opportunity cost of time with children therefore incorporates returns to experience, which are nonlinear. Therefore, estimating a dynastic model which accounts for individual demographics and heterogeneity can be important in understanding the extent of the life-cycle dynamics and help us sort out the importance of different mechanisms leading to persistence in outcomes across generations. The nonlinearity involved in labor supply is realistic; parents labor market time is often not proportional to the number of children they have, and hours in the labor market for a given wage rate are not always flexible and depend on occupation. Furthermore, fertility decisions are made sequentially, and due to age effects, the cost of a child varies over the life cycle. The second condition is nonseparability in preferences, aggregation of the utilities from children, and the feasible set. In our model, the latter is relaxed; that is, the separability of the feasible set across generations. This is because the opportunity costs of the children depend on their education and labor market skills. However, education and labor market skills of children are linked with their parents' skills and education through the production function of education.

\subsection{Optimal discrete choice}

The individual then chooses the sequence of alternatives yielding the highest utility by following the decision rule $I\left(z_{t}, \varepsilon_{t}\right)$, where $\varepsilon_{t}$ is the vector $\left(\varepsilon_{0 t}, \ldots, \varepsilon_{17 t}\right)$. The optimal decision rules are given by

$$
\begin{aligned}
& I^{o}\left(z_{0}, \varepsilon_{0}\right)=\arg \max _{I} E_{I}\left[\sum_{t=0}^{T} \beta^{t}\left\{\sum_{k=0}^{17} I_{k t}\left[u_{k t}\left(z_{t}\right)+\varepsilon_{k t}\right]\right\}\right. \\
& \left.+\beta^{T} \lambda N^{-\nu} \sum_{n=1}^{N} U_{g+1, n}\left(x_{n}^{\prime}\right) \mid x\right] \text {, }
\end{aligned}
$$

where the expectations are taken over the future realizations of $z$ and $\varepsilon$ induced by $I^{o}$. In any period $t<T$, the individual's maximization problem can be decomposed into two parts: the utility received at $t$ plus the discounted future utility from behaving optimally in the future. Therefore, we can write the value function of the problem, which represents the expected present discounted value of lifetime utility from following $I^{o}$, given $z_{t}$ and $\varepsilon_{t}$, as

$$
\begin{aligned}
V\left(z_{t+1}, \varepsilon_{t+1}\right)= & \max _{I} E_{I}\left(\sum_{t^{\prime}=t+1}^{T} \beta^{t^{\prime}-t} \sum_{k=0}^{17} I_{k t^{\prime}}\left[u_{k t^{\prime}}\left(z_{t^{\prime}}\right)+\varepsilon_{k t^{\prime}}\right]\right. \\
& \left.+\beta^{T-t} \lambda N^{-\nu} \sum_{n=1}^{N} U_{g+1, n}\left(x_{n}^{\prime}\right) \mid z_{t+1}, \varepsilon_{t+1}\right) .
\end{aligned}
$$


By Bellman's principle of optimality, the value function can be defined recursively as

$$
\begin{aligned}
V\left(z_{t}, \varepsilon_{t}\right)= & \max _{I}\left[\sum_{k=0}^{17} I_{k t}\left\{u_{k t}\left(z_{t}\right)+\varepsilon_{k t}+\beta E\left(V\left(z_{t+1}, \varepsilon_{t+1}\right) \mid z_{t}, I_{k t}=1\right)\right\}\right] \\
= & \sum_{k=0}^{17} I_{k t}^{o}\left(z_{t}, \varepsilon_{t}\right)\left[u_{k t}\left(z_{t}\right)+\varepsilon_{k t}\right. \\
& \left.+\beta \sum_{z^{\prime}} \int V\left(z^{\prime}, \varepsilon\right) f(\varepsilon) d \varepsilon F\left(z^{\prime} \mid z_{t}, I_{k t}^{o}=1\right)\right],
\end{aligned}
$$

where $f(\varepsilon)$ is the continuously differentiable density of $F_{\varepsilon}\left(\varepsilon_{0 t}, \ldots, \varepsilon_{17 t}\right)$, and $F\left(z^{\prime} \mid z_{t}\right.$, $I_{k t}=1$ ) is a transition function for state variables, which is conditional on choice $k$. In this simple version, the transitions of the state variables are deterministic given the choices of labor market experience, time spent with children, and number of children.

Since $\varepsilon_{t}$ is unobserved, we further define the ex ante (or integrated) value function, $V\left(z_{t}\right)$, as the continuation value of being in state $z_{t}$ before $\varepsilon_{t}$ is observed by the individual. Therefore, $V\left(z_{t}\right)$ is given by integrating $V\left(z_{t}, \varepsilon_{t}\right)$ with respect to the density of $\varepsilon_{t}$. Defining the probability of choice $k$ at age $t$ by $p_{k}\left(z_{t}\right)=E\left[I_{k t}^{o}=1 \mid z_{t}\right]$, the ex ante value function can be written as

$$
V\left(z_{t}\right)=\sum_{k=0}^{17} p_{k}\left(z_{t}\right)\left[u_{k t}\left(z_{t}\right)+E_{\varepsilon}\left[\varepsilon_{k t} \mid I_{k t}=1, z_{t}\right]+\beta \sum_{z^{\prime}} V\left(z^{\prime}\right) F\left(z^{\prime} \mid z_{t}, I_{k t}=1\right)\right] .
$$

This representation of the problem is a not new or is it unique to dynastic models, ${ }^{14}$ but pedagogically it shows that $V\left(z_{t}\right)$ is a function of the CCPs, the expected value of the preference shock, the per-period utility, the transition function, and the ex ante continuation value. All components except the conditional probability and the ex ante value function are primitives of the initial decision problem. By writing the CCPs as a function of just the primitives and the ex ante value function, we can characterize the optimal solution of the problem (i.e., the ex ante value function) as implicitly dependent on just the primitives of the original problem.

As is standard in the dynamic discrete choice literature, we define the conditional value function, $v_{k}\left(z_{t}\right)$, as the present discounted value (net of $\varepsilon_{t}$ ) of choosing $k$ and behaving optimally from period $t$ onward:

$$
v_{k}\left(z_{t}\right)=u_{k t}\left(z_{t}\right)+\beta \sum_{z^{\prime}} V\left(z^{\prime}\right) F\left(z^{\prime} \mid z_{t}, I_{k t}=1\right) .
$$

The conditional value function is the key component to the CCPs. Equation (10) can now be rewritten using the individual's optimal decision rule at $t$ to solve

$$
I^{o}\left(z_{t}, \varepsilon_{t}\right)=\arg \max _{I} \sum_{k=0}^{17} I_{k t}\left[v_{k}\left(z_{t}\right)+\varepsilon_{k t}\right] .
$$

\footnotetext{
${ }^{14}$ See, for example, Aguirregabiria and Mira (2002).
} 
Therefore, the probability of observing choice $k$, conditional on $z_{t}$, is $p_{k}\left(z_{t}\right)$ and is found by integrating overt $\varepsilon_{t}$ in the decision rule in equation (15):

$$
\begin{aligned}
p_{k}\left(z_{t}\right) & =\int I^{o}\left(z_{t}, \varepsilon_{t}\right) f_{\varepsilon}\left(\varepsilon_{t}\right) d \varepsilon_{t} \\
& =\int\left[\prod_{k \neq k^{\prime}} 1\left\{v_{k}\left(z_{t}\right)-v_{k^{\prime}}\left(z_{t}\right) \geq \varepsilon_{t k^{\prime}}-\varepsilon_{k t}\right\}\right] f_{\varepsilon}\left(\varepsilon_{t}\right) d \varepsilon_{t} .
\end{aligned}
$$

Therefore, $p_{k}\left(z_{t}\right)$ is now entirely a function the primitives of the model (i.e., $u_{k t}\left(z_{t}\right), \beta$, $F\left(z_{t+1} \mid z_{t}, I_{k t}=1\right)$, and $\left.f_{\varepsilon}\left(\varepsilon_{t}\right)\right)$ and the ex ante value function. Hence substituting equation (16) into equation (13) gives an implicit equation defining the ex ante value function as a function of only the primitives of the model.

\section{A generiC ESTIMATOR OF THE LIFE-CYCLE DYNASTIC DiSCRETE CHOICE MODEL}

We use a partial solution, multistage estimation procedure to accommodate the nonstandard features of the model. By assuming stationarity across generations and discrete state space in the dynamic programming problem, we obtain an analytical representation of the value function. The alternative value function depends on the CCPs, the transition functions of the state variables, and the structural parameters of the model. In the first stage, we estimate the CCPs and the transition functions. The second stage forms either moment conditions or likelihood functions to estimate the remaining structural parameters using a PML or a GMM, respectively. For each iteration in the estimation procedure, the CCPs are used to generate a value function representation to form the terminal value in the life-cycle problem, which can then be solved by backward induction to obtain the life-cycle valuation functions.

\subsection{An alternative representation of the problem}

The alternative representation of the continuation value of the intergenerational problem is developed below. The Hotz and Miller estimation technique for standard singleagent problems is adapted to the dynastic problem using the following representation. Define $N_{T}\left(z_{T}\right)$ to be the total number of children at the end of the life cycle given state variable $z_{T}$. In addition, we recursively define a transition function $F_{k}^{o}\left(z_{t^{\prime}} \mid z_{t}\right)$ for the oneperiod-ahead $t^{\prime}-t$ :

$$
F_{k}^{o}\left(z_{t^{\prime}} \mid z_{t}\right)= \begin{cases}F\left(z_{t^{\prime}} \mid z_{t}, I_{k t}=1\right) & \text { for } t^{\prime}-t=1, \\ \sum_{r=0}^{17} \sum_{z_{t^{\prime}-1}} p_{r}\left(z_{t^{\prime}-1}\right) F\left(z_{t^{\prime}} \mid z_{t^{\prime}-1}, I_{r t^{\prime}-1}=1\right) F_{k}^{o}\left(z_{t^{\prime}-1} \mid z_{t}\right) & \text { for } t^{\prime}-t>1,\end{cases}
$$

This function is a recursive formulation that determines the probability of a future state $z_{t^{\prime}}$ conditional on current state $z_{t}$ and a current choice $k$.

Proposition 1. There exists an alternative representation for the ex ante conditional value function at time $t$ that is a function of just the primitives of the problem and the 
CCPs:

$$
\begin{aligned}
v_{k}\left(z_{t}\right)= & u_{k t}\left(z_{t}\right)+\sum_{t^{\prime}=t+1}^{T} \beta^{t^{\prime}-t} \\
& \times \sum_{s=0}^{17} \sum_{z_{t^{\prime}}} p_{s}\left(z_{t^{\prime}}\right)\left[u_{s t^{\prime}}\left(z_{t^{\prime}}\right)+E_{\varepsilon}\left(\varepsilon_{s t^{\prime}} \mid I_{s t^{\prime}}=1, z_{t^{\prime}}\right)\right] F_{k}^{o}\left(z_{t^{\prime}} \mid z_{t}\right) \\
& +\lambda \beta^{T-t} \sum_{z_{T}} N_{T}\left(z_{T}\right)^{-\nu} \sum_{n=1}^{N_{T}} \sum_{x} V\left(x^{\prime}\right) \sum_{s=0}^{K_{T}} M_{k}^{n}\left(x^{\prime} \mid z_{T}\right) p_{s}\left(z_{T}\right) F_{k}^{o}\left(z_{T} \mid z_{t}\right),
\end{aligned}
$$

where the intergenerational transition function for the nth child born in a parent's life cycle, $M_{k}^{n}\left(x^{\prime} \mid z_{T}\right)=M\left(x^{\prime} \mid z_{T}\right)$, is conditional on a choice $I_{k T}=1$.

The representation in Proposition 1 highlights the main contribution of this paper. There are three components in equation (17). The first two are normally found in the finite horizon discrete choice dynamic programming model, and are standard in stationary dynamic discrete choice models. The last components is the dynastic component that is nonstandard. There are two points worth noting. The first is that without further restrictions, the third component of equation (17), does not have the finitestate-dependence property, which normally simplifies the estimation of life-cycle discrete choice models. See Altug and Miller (1998), Gayle and Miller (2004), Arcidiacono and Miller (2011, 2015), Gayle and Golan (2012), and Gayle (2015) for discussion and use of the finite-state-dependence property. Second, an alternative used in literature which estimates or calibrates dynastic models ${ }^{15}$ is to replace the dynastic component in equation (17) with a reduced form approximation, and then treat the model as a finite horizon model with a reduced form terminal value function. This reduced form approximation, however, is not in general policy invariant. Therefore, we pursue an alternative strategy which builds on the ideas in Aguirregabira and Mira (2002) and Pesendorfer and Schmidt-Dengler (2008).

Let $e_{k}(p, z)$ represent the expected preference shocks conditional on choice $k$ being optimal in state $z$. The expected preference shocks are written in this notation to convey that the expected value of shock is a function of the CCPs (see Hotz and Miller (1993)). For example, in the type 1 extreme value case, $e_{k}(p, z)$ is given by $\gamma-\ln \left[p_{k}(z)\right]$, where $\gamma$ is Euler's constant. From the representation in Proposition 1, we can define the ex ante conditional lifetime utility at period $t$, excluding the dynastic component as

$$
U_{k}\left(z_{t}\right)=u_{k t}\left(z_{t}\right)+\sum_{t^{\prime}=t+1}^{T} \beta^{t^{\prime}-t} \sum_{s=0}^{17} \sum_{z_{t^{\prime}}} p_{s}\left(z_{t^{\prime}}\right)\left[u_{s t^{\prime}}\left(z_{t^{\prime}}\right)+e_{s}\left(p, z_{t^{\prime}}\right)\right] F_{k}^{o}\left(z_{t^{\prime}} \mid z_{t}\right) .
$$

\footnotetext{
${ }^{15}$ See, for example, Rios-Rull and Sanchez-Marcos (2002).
} 
Because $U_{k}\left(z_{t}\right)$ is a function of just the primitives of the problem and the CCPs, we can write an alternative representation for the ex ante value function at time $t$ :

$$
\begin{aligned}
V\left(z_{t}\right)= & \sum_{k=0}^{17} p_{k}\left(z_{t}\right)\left[U_{k}\left(z_{t}\right)+e_{k}\left(p, z_{t}\right)\right. \\
& \left.+\lambda \beta^{T-t} \sum_{z_{T}} N_{T}\left(z_{T}\right)^{-\nu} \sum_{n=1}^{N_{T}} \sum_{x} V\left(x^{\prime}\right) \sum_{s=0}^{K_{T}} M_{k}^{n}\left(x^{\prime} \mid z_{T}\right) p_{s}\left(z_{T}\right) F_{k}^{o}\left(z_{T} \mid z_{t}\right)\right] .
\end{aligned}
$$

Equation (18) is satisfied at every state vector $z_{t}$. The problem is stationary over generations, so $z_{t}=x$ at period $t=0$ because there is no history of decisions in the state space, and hence the initial state space has finite support on the integers $\{1, \ldots, X\}$. We define the optimal lifetime intergenerational transition function as $M_{k}^{o}\left(x^{\prime} \mid x\right)=\sum_{z_{T}} \sum_{n=1}^{N_{T}\left(z_{T}\right)} \sum_{s=0}^{K_{T}} p_{s}\left(z_{T}\right) M_{k}^{n}\left(x^{\prime} \mid z_{T}\right) F_{k}^{o}\left(z_{T} \mid x\right)$. The matrix $M_{k}^{o}$ can be interpreted as the probability that an average descendant of the individual with characteristic $x^{\prime}$, given that his parents have characteristics $x$, chooses decision $k$ in the first period and behaves optimally from period 1 to $T$ of the parent's life cycle. Now, we can express the components of equation (18) in vector or matrix form:

$V_{0}=\left[\begin{array}{c}V(1) \\ \cdot \\ \cdot \\ \cdot \\ V(X)\end{array}\right], \quad U(k)=\left[\begin{array}{c}U_{k}(1) \\ \cdot \\ \cdot \\ \cdot \\ U_{k}(X)\end{array}\right], \quad E(k)=\left[\begin{array}{c}e_{k}(p, 1) \\ \cdot \\ \cdot \\ \cdot \\ e_{k}(p, X)\end{array}\right], \quad P(k)=\left[\begin{array}{c}p_{k}(1) \\ \cdot \\ \cdot \\ \cdot \\ p_{k}(X)\end{array}\right]$,

$\iota_{X}=\left[\begin{array}{c}1 \\ \cdot \\ \cdot \\ 1\end{array}\right]_{X x 1} \quad$ and $\quad M^{o}(k)=\left[\begin{array}{ccc}M_{k}^{o}(1 \mid 1) & \ldots & M_{k}^{o}(X \mid 1) \\ \cdot & & \\ \cdot & & \\ \cdot & & \\ M_{k}^{o}(1 \mid X) & \ldots & M_{k}^{o}(X \mid X)\end{array}\right]$.

Using these components, the vector of the ex ante value function can be expressed as

$$
V_{0}=\sum_{k=0}^{K} P(k) \otimes\left[U(k)+E(k)+\lambda \beta^{T} N_{k}^{-\nu} \otimes M^{o}(k) V_{0}\right],
$$

where $\otimes$ refers to element-by-element multiplication, $N_{k}(x)=\sum_{z_{T}} N_{T}\left(z_{T}\right) F_{k}^{o}\left(z_{T} \mid x\right)$, and $N_{k}=\left(N_{k T}(1), \ldots, N_{k T}(X)\right)^{\prime}$. Rearranging the terms and solving for $V_{0}$, we obtain

$$
V_{0}=\left[I_{X}-\lambda \beta^{T} \sum_{k=0}^{17}\left\{P(k) \iota_{X}^{\prime}\right\} \otimes\left(N_{k}^{-\nu} \otimes M^{o}(k)\right)\right]^{-1} \sum_{k=0}^{17} P(k)[U(k)+E(k)],
$$

where $I_{X}$ denotes the $X \times X$ identity matrix. Equation (20) is based on the dominant diagonal property, which implies that the matrix $I_{X}-\lambda \beta^{T} \sum_{k=0}^{17}\left\{P(k) \iota_{X}^{\prime}\right\} \otimes\left(N_{k}^{-\nu} \otimes M^{o}(k)\right)$ 
is invertible. The representation is obtained by combining known results ${ }^{16}$ from discrete choice estimation of stationary infinite-horizon problems with the finite horizon properties of the dynastic life-cycle model.

\subsection{Estimation}

We parameterized the period utility by a vector $\theta_{2}, u_{k t}\left(z_{t}, \theta_{2}\right)$; the period transition on the observed states is parameterized by a vector $\theta_{3}, F\left(z_{t} \mid z_{t-1}, I_{k T}=1, \theta_{3}\right)$; the intergenerational transitions on permanent characteristics is parameterized by a vector $\theta_{4}$, $M^{n}\left(x^{\prime} \mid z_{T+1}, \theta_{4}\right)$; and the earnings function is characterized by a vector $\theta_{5}, w_{t}\left(x, h_{t}, \theta_{5}\right)$. Therefore, the conditional value functions, decision rules, and choice probabilities now also depend on $\theta \equiv\left(\theta_{2}, \theta_{3}, \theta_{4}, \theta_{5}, \beta, \lambda, \nu\right)$. Standard estimates of dynamic discrete choice models involve forming the likelihood functions from the CCPs derived in equation (16). This involves solving the value function for each iteration of the likelihood function. The method used to solve the value function depends on the nature of the optimization problems and normally falls into one of two cases:

(i) Finite-horizon problems: The problem has an end date (as in a standard life-cycle problem); hence future value function is obtained by backwards induction.

(ii) Stationary infinite-horizon problem: The valuation is obtained by a contraction mapping.

A dynastic discrete choice model in unusual because it involves both a finite-horizon problem and an infinite-horizon problem. Solving both problems for each iteration of the likelihood function is computationally infeasible for all but the simplest of models. We avoid solving the stationary infinite-horizon problem in estimation by replacing the terminal value in the life-cycle problem with equation (20). This converts the problem into a finite-horizon problem that can be solved by backward recursion, with the flow utility function given by

$$
v_{k}\left(z_{T}\right)=u_{k T}\left(z_{T}\right)+\lambda N_{T}\left(z_{T}\right)^{-\nu} \sum_{x^{\prime}} V\left(x^{\prime}\right) \sum_{n=1}^{N_{T}} M_{k}^{n}\left(x^{\prime} \mid z_{T}\right) .
$$

The per-period utility in the terminal period, $u_{k T}\left(z_{T}\right)$, is parameterized by $\theta_{2}$. The intergenerational transition function, $M_{k}^{n}\left(x^{\prime} \mid z_{T}\right)$, can be treated as known since it can be estimated from the data. Given $F_{\varepsilon}\left(\varepsilon_{0 t}, \ldots, \varepsilon_{17 t}\right)$ and calculating $V\left(x^{\prime}\right)$ via equation (20), ${ }^{17}$ we can calculate the ex ante value function at $T$ using $V\left(z_{T}\right)=$ $\sum_{k=0}^{17} \int I_{k I}^{0}\left(z_{T}, \varepsilon_{T}\right)\left[v_{k}\left(z_{T}\right)+\varepsilon_{k T}\right] f_{\varepsilon}\left(\varepsilon_{T}\right) d \varepsilon_{T}$. The conditional value function for $T-1$ is given by $v_{k}\left(z_{T-1}\right)=u_{k T-1}\left(z_{T-1}\right)+\beta \sum_{z_{T}} V\left(z_{T}\right) F\left(z_{T} \mid z_{T-1}, I_{k T}=1\right)$. This is continued backward given $v_{k}\left(z_{T-1}\right)$ to form value function at $T-2$, and so on.

\footnotetext{
${ }^{16}$ See Aguirregabira and Mira (2002) and Pesendorfer and Schmidt-Dengler (2008) for the use and derivation of this inversion in the context of stationary infinite horizon problems.

${ }^{17}$ This manipulation is possible because the alternative value function in equation (20) is a function of only the parameters of the model and the CCPs. The CCPs can be estimated directly from the data then backward recursion becomes possible because the decision in the last period, $T$, is similar to a static problem when the value of children is replaced with equation (20).
} 
The backward induction procedure outlined above shows that only $M_{k}^{n}\left(x^{\prime} \mid z_{T}\right)$ in equations (21) and (20) depends on the next generation's outcome. Thus, we can estimate the intergenerational problem with only two generations of data, as is the case in the standard stationary discrete choice models (see for example Rust (1987)). To estimate the intergenerational problem, we let $I_{d t g}, z_{d t g}$, and $\varepsilon_{d t g}$, respectively, indicate the choice, observed state, and unobserved state at age $t$ in the generation $g$ of dynasty $d$. Forming the CCPs for each individual in the first observed generation of dynasty $d$ at all ages $t$ yields the components necessary for estimation. Estimation proceeds in two steps.

Step 1: In the first step, we estimate the CCP, transition, and earnings functions necessary to compute the inversion in equation (20). The expectation of observed choices conditional on the observed state variables gives an empirical analog to the CCPs at the true parameter values of the problem, $\theta_{1}^{o}$, allowing us to estimate the CCPs; we denote this estimate by $\widehat{p_{k}\left(z_{d t 1}\right)}$. We also estimate $\theta_{3}, \theta_{4}$, and $\theta_{5}$, which parameterize the transition and earnings functions $F\left(z_{t} \mid z_{t-1}, I_{k T}=1, \theta_{3}\right), M^{n}\left(x^{\prime} \mid z_{T+1}, \theta_{4}\right)$, and $w_{t}\left(x, h_{t}, \theta_{5}\right)$, respectively, in this step.

Step 2: The second step can be estimated two ways, the first is a PML (as used in Aguirregabira and Mira (2002)) and the second is a GMM (as used in the original Hotz and Miller (1993)). We can use a PML method and not a pure maximum likelihood estimator because part of the likelihood function is concentrated out using the data. With D dynasties, the PML estimates of $\theta_{0}=\left(\theta_{2}, \beta, \lambda, \nu\right)$ are obtained via

$$
\widehat{\theta}_{0 \mathrm{PML}}=\underset{\theta_{0}}{\arg \max }\left(\sum_{d t 1=1}^{D} \sum_{t=0}^{T} \sum_{k}^{17} I_{d t 1} \ln \left[p_{k}\left(z_{d t 1} ; \theta_{0}, \widehat{\theta}_{3}, \widehat{\theta}_{4}, \widehat{\theta}_{5}\right)\right]\right),
$$

where $p_{k}\left(z_{d t 1} ; \theta_{0}, \widehat{\theta}_{3}, \widehat{\theta}_{4}, \widehat{\theta}_{5}\right)$ is the CCP defined in equation (16) with the conditional value function replaced with $v_{k}\left(z_{d t 1}, \theta_{0}, \widehat{\theta}_{3}, \widehat{\theta}_{4}, \widehat{\theta}_{5}\right)$, which is calculated by backward recursion using the estimated choice probabilities and the transition functions outlined in Step 1.

An alternative second-step GMM estimator is formed using the inversion found in Hotz and Miller (1993). Under the assumption that $\varepsilon$ is distributed independently and identically as type I extreme values, then the Hotz and Miller inversion implies that

$$
\begin{array}{r}
\log \left(p_{k}\left(z_{d t 1} ; \theta_{0}, \widehat{\theta}_{3}, \widehat{\theta}_{4}, \widehat{\theta}_{5}\right) / p_{K}\left(z_{d t 1} ; \theta_{0}, \widehat{\theta}_{3}, \widehat{\theta}_{4}, \widehat{\theta}_{53}\right)\right) \\
\quad=v_{k}\left(z_{d t 1}, \theta_{0}, \widehat{\theta}_{3}, \widehat{\theta}_{4}, \widehat{\theta}_{5}\right)-v_{K}\left(z_{d t 1}, \theta_{0}, \widehat{\theta}_{3}, \widehat{\theta}_{4}, \widehat{\theta}_{5}\right)
\end{array}
$$

for any normalized choice $K$. We can use $\widehat{p_{k}\left(z_{d t 1}\right)}$, estimated from Step 1, to form an empirical counterpart to equation (23) and estimate the parameters of our model. The moment conditions can be obtained from the difference in the conditional valuation functions calculated for choice $k$ and a base choice(say $K=0$ ). The following moment conditions are produced for an individual at age $t \in\{17, \ldots, 55\}$ :

$$
\xi_{j d t}\left(\theta_{0}\right) \equiv v_{k}\left(z_{d t 1}, \theta_{0}, \widehat{\theta}_{3}, \widehat{\theta}_{4}, \widehat{\theta}_{5}\right)-v_{0}\left(z_{d t 1}, \theta_{0}, \widehat{\theta}_{3}, \widehat{\theta}_{4}, \widehat{\theta}_{5}\right)-\ln \left[\widehat{p_{k}\left(z_{d t 1}\right)} / \widehat{p_{0}\left(z_{d t 1}\right)}\right] .
$$


Therefore, there are 17 orthogonality conditions and thus $j=1, \ldots, 17$. Letting $\xi_{d t}\left(\theta_{0}\right)$ be the vector of moment conditions at $t$, these vectors are defined as $\xi_{d t}\left(\theta_{0}\right)=$ $\left(\xi_{1 d t}\left(\theta_{0}\right), \xi_{2 d t}\left(\theta_{0}\right), \ldots, \xi_{17 d t}\left(\theta_{0}\right)\right)^{\prime}$. Therefore, $E\left[\xi_{d t}\left(\theta_{0}^{o}\right) \mid z_{d t}\right]$ converges to 0 for every consistent estimator of true CCPs, $p_{k}\left(z_{d t 1} ; \theta_{0}, \widehat{\theta}_{3}, \widehat{\theta}_{4}, \widehat{\theta}_{5}\right)$, for $t \in\{17, \ldots, 55\}$, and where $\theta_{0}^{o}$ is the true parameter of the model. Define $\xi_{d}\left(\theta_{0}\right) \equiv\left(\xi_{d 1}\left(\theta_{0}\right)^{\prime}, \ldots, \xi_{d T}\left(\theta_{0}\right)^{\prime}\right)^{\prime}$ as the vector of moment restrictions for a given individual over time and define a weight matrix as $\Phi\left(\theta_{0}\right) \equiv E_{t}\left[\xi_{d}\left(\theta_{0}\right) \xi_{d}\left(\theta_{0}\right)^{\prime}\right]$. Then the GMM estimate of $\theta_{0}$ is obtained via

$$
\widehat{\theta}_{02 \mathrm{SGMM}}=\underset{\theta_{0}}{\arg \min }\left[1 / D \sum_{d=1}^{D} \xi_{d}\left(\theta_{0}\right)\right]^{\prime} \widehat{\Phi}\left[1 / D \sum_{d=1}^{D} \xi_{d}\left(\theta_{0}\right)\right],
$$

where $\widehat{\Phi}$ is a consistent estimator of $\Phi\left(\theta^{\circ}\right)$.

\subsection{Monte Carlo study}

We present a numerical example of a model with human capital investments and intergenerational transfers. We use the example to examine the performance of the proposed estimation technique. Using simulated data from the numerical example, we estimate the parameters of the model using the NFXP and PML estimators. The estimation is done for varying sample sizes (i.e., for 1000, 10,000, 20,000, and 40,000).

NFXP estimation of life-cycle dynastic models is possible only in the simplest dynastic structure. Hence for the Monte Carlo study we choose a simple model which can be estimated by both NFXP and PML. To the best of our knowledge, there is no empirical application of life-cycle dynastic model which is estimated by NFXP. Instead, all the empirical application of life-cycle dynastic model specify the terminal value at the end of an individual's life cycle as a reduced-form function of the state variables. Dynastic models estimated in this fashion are not suitable for conducting counterfactual policy analysis.

For illustration purposes, we start with the model in which the per-period utility function, $u_{k}\left(z_{t}\right)$, has a linear form. In each period, $t \in\{0,1\}$, the individual chooses whether to invest or not, $I_{k} \in\{0,1\}$. We assume that individuals can have at most one child, $N \leq 1$. The utilities associated with each choice are given by

$$
u_{k}\left(z_{t}\right)=\left\{\begin{array}{ll}
z_{t} & \text { if } k=0 \\
(1-\theta) z_{t} & \text { if } k=1
\end{array}\right\}
$$

where $F_{\varepsilon}\left(\varepsilon_{t}\right)$ is the distribution of the choice-specific, unobservable part of the utility; it is assumed to be independently distributed type 1 extreme value.

In the environment in this example, the individual begins the life cycle with a particular set of character traits denoted by $z_{t} \in(0.5,0.6,0.7,0.8,0.9)$. Note that at $t=0$ the individual has not made any choices yet, so the vector $z_{0}$ depends fully on initial characteristics $x$. The value of $z_{1}$ is given by the transformation function $F_{k}\left(z_{t} \mid z_{t-1}\right)$ that given 
by the transition matrix:

$$
F_{0}\left(z_{t} \mid z_{t-1}\right)=\left(\begin{array}{ccccc}
0.85 & 0.13 & 0.02 & 0 & 0 \\
0.04 & 0.85 & 0.09 & 0.02 & 0 \\
0.01 & 0.04 & 0.85 & 0.09 & 0.01 \\
0 & 0.01 & 0.05 & 0.85 & 0.09 \\
0 & 0 & 0 & 0 & 1
\end{array}\right)
$$

and

$$
F_{1}\left(z_{t} \mid z_{t-1}\right)=\left(\begin{array}{ccccc}
1 & 0 & 0 & 0 & 0 \\
0.1 & 0.9 & 0 & 0 & 0 \\
0.13 & 0.27 & 0.6 & 0 & 0 \\
0.01 & 0.11 & 0.28 & 0.6 & 0 \\
0 & 0.04 & 0.13 & 0.23 & 0.6
\end{array}\right)
$$

The individual's traits in the next period are determined by the probabilities in the corresponding row, where each row corresponds to one of the initial values $z_{0} \in$ $(0.5,0.6,0.7,0.8,0.9)$, and each column represents character traits in the next period, $z_{1} \in(0.5,0.6,0.7,0.8,0.9)$. The transition is such that an individual with character traits $z_{0}=0.5$ who chooses not to have a child, such that the choice vector $I_{0}=0$, will have characteristics $z_{1}=0.5$ with a probability of 0.85 . In this simplified model, the next generation's initial characteristics $z_{0}^{\prime}$ depend only on the sum of the financial investment decisions in the life cycle.

The educational outcome of the offspring is determined by the intergenerational transition function:

$$
M\left(z_{0}^{\prime} \mid z_{T+1}\right)=\left(\begin{array}{ccccc}
1 & 0 & 0 & 0 & 0 \\
0 & 0.1 & 0.4 & 0.4 & 0.1 \\
0 & 0 & 0.04 & 0.06 & 0.9
\end{array}\right)
$$

where $z_{T+1}$ can take values in $\{0,1,2\}$. The next generation's starting character traits are determined by the probabilities given in the row, where each row corresponds to one of the values of $z_{T+1} \in(0,1,2)$ and the first row represents investment level $z_{T+1}=0$. If the individual invests nothing, then the next generation will have the lowest consumption value with complete certainty. The transition is such that an individual who opts to invest twice in the life cycle has a probability of 0.9 that the next generation will start his life cycle with the characteristics $z_{0}^{\prime}=0.9$.

We simulated the model for the parameter values, $\left(\theta_{2}, \beta, \lambda\right)=(0.25,0.8,0.95)$, where $\theta$ is the structural parameter of interest that gives the marginal cost of investment, and $\lambda$ and $\beta$ are the generational and time discount factors, respectively. We solve the dynamic problem for datasets of 1000, 10,000, 20,000, 40,000 individual dynasties and repeat the simulation 100 times. For the CCP estimation, the initial consistent estimates are esti- 
TABLE 1. Simplified discrete choice Monte Carlo simulation results.

\begin{tabular}{|c|c|c|c|c|c|c|c|c|}
\hline & \multicolumn{4}{|c|}{ Pseudo Maximum Likelihood } & \multicolumn{4}{|c|}{ Nested Fixed Point (ML) } \\
\hline & \multicolumn{4}{|c|}{ Sample Size } & \multicolumn{4}{|c|}{ Sample Size } \\
\hline & 1000 & 10,000 & 20,000 & 40,000 & 1000 & 10,000 & 20,000 & 40,000 \\
\hline \multicolumn{9}{|c|}{$\theta=0.25$} \\
\hline Mean & 0.24473 & 0.24935 & 0.24886 & 0.24881 & 0.22714 & 0.24571 & 0.23320 & 0.24477 \\
\hline Std. Dev. & 0.04991 & 0.01328 & 0.00915 & 0.00668 & 0.04884 & 0.01354 & 0.02135 & 0.01019 \\
\hline Bias & -0.00527 & -0.00065 & -0.00114 & -0.00119 & -0.02286 & -0.00429 & -0.01680 & -0.00523 \\
\hline MSE & 0.00249 & 0.00017 & 0.00008 & 0.00005 & 0.00288 & 0.00020 & 0.00073 & 0.00013 \\
\hline \multicolumn{9}{|c|}{$\lambda=0.8$} \\
\hline Mean & 0.80425 & 0.79745 & 0.79797 & 0.79673 & 0.77538 & 0.78966 & 0.76934 & 0.78855 \\
\hline Std. Dev. & 0.11241 & 0.03175 & 0.02157 & 0.01587 & 0.09211 & 0.03244 & 0.03656 & 0.02063 \\
\hline Bias & 0.00425 & -0.00255 & -0.00203 & -0.00327 & -0.02462 & -0.01034 & -0.03066 & -0.01145 \\
\hline MSE & 0.01253 & 0.00100 & 0.00046 & 0.00026 & 0.00901 & 0.00115 & 0.00226 & 0.00055 \\
\hline \multicolumn{9}{|c|}{$\beta=0.95$} \\
\hline Mean & 0.94208 & 0.95245 & 0.95037 & 0.95136 & 0.93441 & 0.95227 & 0.94603 & 0.95027 \\
\hline Std. Dev. & 0.06276 & 0.01893 & 0.01301 & 0.00934 & 0.05322 & 0.01983 & 0.01820 & 0.01236 \\
\hline Bias & -0.00792 & 0.00245 & 0.00037 & 0.00136 & -0.01559 & 0.00227 & -0.00397 & 0.00027 \\
\hline MSE & 0.00396 & 0.00036 & 0.00017 & 0.00009 & 0.00305 & 0.00039 & 0.00034 & 0.00015 \\
\hline Avg. Comp. time & 0.65 & 2.88 & 6.06 & 12.60 & 347.6 & 376.4 & 467.5 & 509.8 \\
\hline
\end{tabular}

Note: The pseudo maximum likelihood corresponds to the estimation conducted by the new estimator using PML and maximum likelihood (ML) estimation is by the nested fixed point (NFXP). All simulations were conducted using the programming language GAUSS on a 2-CPU 1.66-GHz, 3-GB RAM laptop computer. The unit of time is seconds. The mean, empirical standard deviation, bias, and mean squared error (MSE) of each parameter estimate are reported in the respective column for each sample size. The bias and the MSE are calculated relative to the original data-generating value of the parameter. The data-generating value of the parameter is also reported at the center of the summary statistics block for that parameter.

mated nonparametrically using the generated sample. Next, we estimate the model by NFXP and PML. ${ }^{18}$

Table 1 presents the results of the estimation. We find that the finite-sample properties of the estimators improve monotonically with sample size. In the NFXP estimation, the mean square error (MSE) of $\theta$ drops quickly as the sample size increases. The results for the discount factors are similar: MSEs fall as the sample size increases. In the PML estimation, we observe a similar pattern for all estimators. We obtain similar results from the NFXP and PML parameters. For the sample size of 1000, the PML estimate of the MSE of $\theta_{0}$ is 0.00249 compared with 0.00288 from the NFXP. The PML estimate of the MSE of $\lambda$ is 0.01253 compared with 0.00901, and the PML estimate of the MSE of $\beta$ is 0.00396 compared with 0.00305 . For the sample sizes of $10,000,20,000$, and 40,000 , the MSEs obtained from PML estimation is lower than the MSEs obtained from the NFXP, but the magnitudes are still very close. In terms of biases, the two estimation algorithms are also quite similar. The major difference between the two estimation algorithms is computational time, which varies greatly between the NFXP and PML even though we

\footnotetext{
${ }^{18}$ As illustrated in the estimation section, intergenerational models at the final step can be estimated either by the PML or GMM method. For this simulation study, we used the PML because it is more comparable to the full solution maximium likelihood.
} 
simulate a very simple model. The average computational time for the NFXP for a sample of 1000 is 347.6 seconds, but it is only 0.65 seconds for the PML estimation, meaning the PML was 530 times faster. For the sample size of 40,000, computation times are 509.8 and 12.6 seconds for the NFXP and PML, respectively, a ratio of 40.4 .

\section{Extensions}

The dynastic framework developed so far in this paper has three major drawbacks. First, parts of the parental investment and transfers from parents to children are monetary in nature. Additionally, for exposition purpose we assume that there were not borrowing or saving. Monetary investment and/or parental transfers, such as paying for college or purchasing a house for their children, are most naturally characterized as a continuous choice. Also it is natural to introduce borrowing and saving as a continuous choice. Second, the framework assumes that gender does not matter. However, there are significant differences in the cost, choices, and opportunities over an individual's lifetime that are gender specific. Third, which is related to gender but not specific to it, is that individuals normally form households and it takes a man and a woman to reproduce, and fertility is central to the model. In this section, we consider extensions to the basic framework that account for these three shortcomings.

\subsection{Continuous choice and transfer}

For the estimation technique developed above to be applicable to a dynastic framework, two features must be present. First, all choices must be discrete, and second, all systematic state variables, at the initial stage and in every period during the life cycle, must have a discrete support. We replace these assumptions with two weaker assumptions. The first is that there must be at least one discrete choice variable. This requirement is easily satisfied as birth decision is naturally discrete. The second is that the initial systematic state variables (i.e., endowment that an individual starts adult life with) must belong to a finite set with discrete support. This is weaker than the original assumption and is a less restrictive requirement; it is satisfied in a nontrivial number of economic dynastic models-for example, in models where human capital is the major intergenerational transfer and even in models of bequests once the amount transferred is discretized. In practice, in most dynamic programming models, the state space is normally discretized. This requirement, however, relaxes the assumption that state space is discrete for the entire lifetime and that all choice variables are discrete. While bequests and initial wealth still must be discrete, the framework allows for any transfers and investments the parents make during their lifetime and map into discrete initial conditions of the child, such as education, houses, or other assets that are discrete in nature. If these assumptions are satisfied, then we can modify the representation and then use the estimation strategy for the mixed discrete and continuous choice model. ${ }^{19}$

\footnotetext{
${ }^{19}$ See Altug and Miller (1998), Gayle and Miller (2004), Gayle and Golan (2012), and Gayle (2015) for application of CCPs estimators with mixed discrete and continuous choices.
} 
For illustration purposes, we extend our framework to include continuous choice of assets and bequests, assuming that we observed data on the per-period assets, $A_{t}$, which is continuous. We assume that individuals beginning their life as adults with asset level $A_{0}$. This level is a bequest from the parents. The initial level of assets, $j$, is discrete with: $A_{0}=\left[A_{0}^{1}, \ldots, A_{0}^{J}\right]$. The budget constraint is given by

$$
A_{t+1}-(1+r) A_{t}=w_{t}\left(x, h_{t}\right)-p c_{n t}-c_{t},
$$

where $r$ is the interest rate for borrowing and savings, and the right-hand side is the household income net of expenditures on children and consumption. A few remarks are in order. First, in order to map the assets at age $T, A_{T}$, to a discrete bequest level that individuals start their life with, $A_{0}^{\prime}$, we define a transition function $\operatorname{Pr}\left(A_{0}^{\prime}=A_{0}^{j} \mid A_{T}\right)$. Second, there are different ways to model markets completeness or incompleteness that will translate into different restrictions on savings and assets levels. For illustration purposes, we will assume the interior solution for all asset choices and will ignore such restrictions in this presentation. We do not restrict the initial and terminal asset levels to be nonnegative. However, the framework can be adjusted to include all these different types of constraints.

Let us further assume that the parents' asset levels can potentially affect educational outcomes of children: higher savings of parents increase the probability of a higher level of educational attainment of the child. ${ }^{20}$ We redefine the vector of state variables $z_{t}$ to capture these new assumptions, $z_{t}=\left(\left\{I_{k 1}\right\}_{k=0}^{17}, \ldots,\left\{I_{k t-1}\right\}_{k=0}^{17}, A_{1}, \ldots, A_{t-1}, x\right)$ with $x \in\left\{A_{0}, x_{1}, \ldots, x_{|X|}\right\}$, a discrete set with finite support. Thus $x$ includes all the characteristics that a person is endowed with at the beginning of life. In this application, it included the initial (discrete) levels of assets inherited from the parents. As before, $M\left(x^{\prime} \mid z_{T+1}\right)$ is the intergenerational transition probability of $x$ conditional on a parent's endowment, $x$, and the parent's choices over his/her lifetime. It includes the education, inherited assets, and potentially skills, for example (as well as traits such as gender and race). As before, it is derived from an education production function, $M\left(x^{\prime} \mid z_{T}\right)$, and is augmented to incorporate $\operatorname{Pr}\left(A_{0}^{\prime}=A_{0}^{j} \mid A_{T}\right)$, the assets transition functions.

Let $I_{k t}^{o}$ and $A_{t}^{o}$ be the sequence of optimal choice over the parent's lifetime. Also, plugging the budget constraint in the utility from consumption, we redefine the systematic part of current utility in equation (8) as

$$
u_{k t}\left(z_{t}, A_{t}\right)=u_{1 k t}\left(z_{t}\right)+u_{t}\left[w_{t}\left(x, h_{t}\right)-p c_{n t}-A_{t+1}+(1+r) A_{t}, z_{t}\right] .
$$

Then the lifetime expected utility excluding the dynastic component at the start of an adult's life becomes

$$
U_{g T}(x)=E_{0}\left[\sum_{t=0}^{T} \beta^{t}\left[\sum_{k=0}^{17} I_{k t}^{o}\left\{u_{1 k t}\left(z_{t}, A_{t}^{o}\right)+\varepsilon_{k t}\right\}\right] \mid x\right] .
$$

\footnotetext{
${ }^{20}$ Assets can be a proxy of the ability to pay for college, for example. However, we allow for assets to impact educational outcomes in order to illustrate the general nature of the extension. One can think of the continuous variable as expenditure on children if observed in the data.
} 
The preference shock $\varepsilon_{k t}$ is associated with the discrete choices in period $t$ and not the continuous choice variables; therefore, it is still indexed with $k$. As before, we can write the value function of the problem, which represents the expected present discounted value of lifetime utility from following $I^{o}$ and $A_{t}^{o}$, given $z_{t}$ and $\varepsilon_{t}$, as

$$
\begin{aligned}
V\left(z_{t+1}, \varepsilon_{t+1}\right)= & \max _{I_{t+1}, A_{t+1}} E_{I, A}\left(\left\{\sum_{t^{\prime}=t+1}^{T} \beta^{t^{\prime}-t} \sum_{k=0}^{17} I_{k t^{\prime}}\left[u_{k t^{\prime}}\left(z_{t^{\prime}}, A_{t^{\prime}}\right)+\varepsilon_{k t^{\prime}}\right]\right.\right. \\
& \left.\left.+\beta^{T-t^{\prime}} \lambda N\left(z_{T}\right)^{-\nu} \sum_{n=1}^{N} E_{T}\left[U_{g+1, n}\left(x_{n}^{\prime}\right) \mid z_{T}\right]\right\} \mid z_{t+1}, \varepsilon_{t+1}\right) .
\end{aligned}
$$

By Bellman's principle of optimality, the value function can be defined recursively as

$$
\begin{aligned}
V\left(z_{t}, \varepsilon_{t}\right)= & \sum_{k=0}^{17}\left(I_{k t}^{o}\left(z_{t}, \varepsilon_{t}\right)\left[u_{k t}\left(z_{t}, A_{t}^{o}\left(z_{t}\right)\right)+\varepsilon_{k t}\right]\right. \\
& \left.\left.+\beta \int\left[\int V\left(z^{\prime}, \varepsilon\right) f_{\varepsilon}(\varepsilon) d \varepsilon\right] d F_{k}\left(z^{\prime} \mid z_{t}, A_{t}\right)\right]\right),
\end{aligned}
$$

where $f_{\varepsilon}(\varepsilon)$ is the continuously differentiable density of $F_{\varepsilon}\left(\varepsilon_{0 t}, \ldots, \varepsilon_{17 t}\right)$, and $F_{k}\left(z^{\prime} \mid z_{t}, A_{t}\right)$ is a transition function for state variables that is conditional on choices $I_{k t}^{o}=1$ and $A_{t}=A_{t}^{0}$. Note that $I_{k t}^{o}\left(z_{t}, \varepsilon_{t}\right)$ is a function of $z_{t}$ and $\varepsilon_{t}$, while $A_{t}^{o}\left(z_{t}\right)$ is a function of only $z_{t}$. This is a consequence of the additive separability of the preferences shock, which will not affect the continuous choice as demonstrated below. The ex ante value function is then

$$
\begin{aligned}
V\left(z_{t}\right)= & \sum_{k=0}^{17} p_{k}\left(z_{t}\right)\left[u_{k t}\left(z_{t}, A_{t}^{o}\left(z_{t}\right)\right)+E_{\varepsilon}\left[\varepsilon_{k t} \mid I_{k t}=1, z_{t}\right]\right. \\
& \left.+\beta \int V\left(z^{\prime}\right) d F_{k}\left(z^{\prime} \mid z_{t}, A_{t}\right)\right] .
\end{aligned}
$$

In this form, $V\left(z_{t}\right)$ is now a function of the CCPs, the continuous choice decision rule, the expected value of the preference shock, the per-period utility, the transition function, and the ex ante continuation value. All components except the conditional probability, the continuous choice decision rule and the ex ante value function are primitives of the initial decision problem. By writing the CCPs and the continuous choice decision rule as a function of just the primitives and the ex ante value function, we can characterize the optimal solution of the problem (i.e., the ex ante value function) as implicitly dependent on the primitives of the original problem. Let us define the conditional value function, $v_{k}\left(z_{t}, A_{t}\right)$, as

$$
v_{k}\left(z_{t}\right)=\max _{A_{t}}\left[u_{k t}\left(z_{t}, A_{t}\right)+\beta \int V\left(z^{\prime}\right) d F_{k}\left(z^{\prime} \mid z_{t}, A_{t}\right)\right] .
$$


Therefore, the probability of observing choice $k$, conditional on $z_{t}, p_{k}\left(z_{t}\right)$, is still given by

$$
p_{k}\left(z_{t}\right)=\int\left[\prod_{k \neq k^{\prime}} 1\left\{v_{k}\left(z_{t}\right)-v_{k^{\prime}}\left(z_{t}\right) \geq \varepsilon_{k t}-\varepsilon_{t k^{\prime}}\right\}\right] f_{\varepsilon}\left(\varepsilon_{t}\right) d \varepsilon_{t} .
$$

However, the optimal continuous choice is found in two steps. First, find the optimal choice conditional on $I_{k t}=1$, which is defined as $A_{t k}\left(z_{t}\right)$. This is characterized by the following Euler equation:

$$
\frac{\partial u_{k t}\left(z_{t}, A_{t}\right)}{\partial A_{t}}=-\beta \frac{\partial \int V\left(z^{\prime}\right) d F_{k}\left(z^{\prime} \mid z_{t}, A_{t}\right)}{\partial A_{t}} .
$$

Then substitute it into the conditional valuation function:

$$
v_{k}\left(z_{t}\right)=\left[u_{k t}\left(z_{t}, A_{t k}\left(z_{t}\right)\right)+\beta \int V\left(z^{\prime}\right) d F_{k}\left(z^{\prime} \mid z_{t}, A_{t}\right)\right],
$$

and find the optimal discrete choice:

$$
I^{o}\left(z_{t}, \varepsilon_{t}\right)=\arg \max _{I} \sum_{k=0}^{17} I_{k t}\left[v_{k}\left(z_{t}\right)+\varepsilon_{k t}\right] .
$$

Finally, we obtain the optimal continuous choice by setting $A_{t}^{o}\left(z_{t}\right)=A_{t k}\left(z_{t}\right)$ if $I_{k t}^{o}\left(z_{t}\right.$, $\left.\varepsilon_{t}\right)=1$.

We now can find an alternative value function that is a function of only $p_{k}\left(z_{t}\right)$, $A_{t k}\left(z_{t}\right)$, and the primitives of the model. We can now state a more general version of Proposition 1.

Proposition 2. There exists an alternative representation for the ex ante conditional value function at time $t$ that is a function of only the primitives of the problem and the CCPs as follows:

$$
\begin{aligned}
v_{k}\left(z_{t}\right)= & u_{k t}\left(z_{t}, A_{t k}\left(z_{t}\right)\right) \\
& +\sum_{t^{\prime}=t+1}^{T} \beta^{t^{\prime}-t} \sum_{s=0}^{17} \int\left[p _ { s } ( z _ { t ^ { \prime } } ) \left[u_{s t^{\prime}}\left(z_{t^{\prime}}, A_{t^{\prime} k}\left(z_{t}\right)\right)\right.\right. \\
& \left.+E_{\varepsilon}\left(\varepsilon_{s t^{\prime}} \mid I_{s t^{\prime}}=1, z_{t^{\prime}}\right)\right] d F_{k}^{o}\left(z_{t^{\prime}} \mid z_{t}\right) \\
& +\lambda \beta^{T-t} \int N_{T}\left(z_{T}\right)^{-\nu} \sum_{n=1}^{N_{T}} \sum_{x^{\prime}} V\left(x^{\prime}\right) \\
& \times \sum_{s=0}^{K_{T}}\left[M_{k}^{n}\left(x^{\prime} \mid z_{T}\right) p_{s}\left(z_{T}\right)\right] d F_{k}^{o}\left(z_{T} \mid z_{t}\right),
\end{aligned}
$$


where $F_{k}^{o}\left(z_{t^{\prime}} \mid z_{t}\right)$ is the $t^{\prime}-t$ period-ahead optimal transition function, recursively defined as

$$
F_{k}^{o}\left(z_{t^{\prime}} \mid z_{t}\right)=\left\{\begin{array}{l}
F\left(z_{t^{\prime}} \mid z_{t}, I_{k t}=1, A_{t k}\left(z_{t}\right)\right) \\
\quad \text { for } t^{\prime}-t=1, \\
\sum_{r=0}^{17} \sum_{z_{t^{\prime}-1}} p_{r}\left(z_{t^{\prime}-1}\right) F\left(z_{t^{\prime}} \mid z_{t^{\prime}-1}, I_{r t^{\prime}-1}=1, A_{t^{\prime}-1 k}\left(z_{t^{\prime}-1}\right)\right) F_{k}^{o}\left(z_{t^{\prime}-1} \mid z_{t}\right) \\
\text { for } t^{\prime}-t>1,
\end{array}\right.
$$

where $N_{T}\left(z_{T}\right)$ is the number the children induced from $z_{T}, K_{T}$ is the number of possible choice combinations available to the individual in the terminal period (in which birth is no longer feasible $)$, and $M_{k}^{n}\left(x^{\prime} \mid z_{T}\right)=M\left(x^{\prime} \mid z_{T}\right)$ conditional on $I_{k T}=1$ for the $n$th child born in a parent's life cycle.

This representation is similar to the one in Proposition 1 except for the inclusion of $A_{t k}\left(z_{t}\right)$ and the replacement of an integral for a summation deal with the continuous state variables over the life cycle. The inversion-and hence the estimation-follows through as before except we now need a first-stage consistent estimate of $A_{t k}\left(z_{t}\right)$ as well. This is obtained as $A_{t k}\left(z_{t}\right)=E\left[A_{t} \mid z_{t}, I_{k t}=1\right] .^{21}$

\subsection{Household and gender}

We extend the basic framework to include household decisions and gender. To the best of our knowledge, no other paper estimates dynastic models with household decisions. There are many models of household decisions; here, we show how to extend the model to incorporate a unitary decision-maker. The framework can be extended to deal with collective household decisions: see Gayle, Golan, and Soytas (2014) for an application of this estimation technique to a noncorporative collective model of household behavior. Let an individual's gender, subscripted as $\sigma$, take the value of $m$ for a male and $f$ for a female: $\sigma=\{f, m\}$. Gender is included in the vector of invariant characteristics $x_{\sigma}$. Let $K$ describe the number of possible combinations of actions available to each household. Individuals get married at time zero, and for simplicity we assume there is no divorce (see Gayle, Golan, and Soytas (2014) for an application with marriage and divorce). Households are assumed to live for $T$ periods and die together. Time zero is normalized to account for the normal age gap between married couples, which would imply that men have a longer childhood than women. All individual variables and earnings are indexed by the gender subscript $\sigma$. We omit the gender subscript when a variable refers to the household (both spouses). The state variables are extended to include the gender of the offspring. Let the vector $\zeta_{t}$ indicate the gender of a child born at age $t$, where $\zeta_{t}=1$ if the child is a female and $\zeta_{t}=0$ otherwise. The vector of state variables is expanded to include the gender of the offspring is as follows:

$$
z_{t}=\left(\left\{I_{k 1}\right\}_{k=0}^{K}, \ldots,\left\{I_{k t-1}\right\}_{k=0}^{K}, \zeta_{0}, \ldots, \zeta_{t-1}, x_{f}, x_{m}\right) .
$$

\footnotetext{
${ }^{21}$ We are assuming that there is no additional stochastic element in the determination of $A_{t k}(z)$.
} 
We assume households invest time and money in the children in the household. The function $w_{\sigma t}\left(z_{t}, h_{\sigma t}\right)$ denotes the earnings function; the only difference from the single-agent problem is that gender is included in $z_{t}$ and can thus affect earnings. The total earnings is the sum of individual earnings as $w_{t}\left(z_{t}, h_{t}\right)=w_{1 t}\left(z_{t}, h_{f t}\right)+w_{2 t}\left(z_{t}, h_{m t}\right)$, where $h_{t}=\left(h_{f t}, h_{m t}\right)$. The educational outcome of the parents' offspring is mapped from the same parental inputs as the single-agent model: income and time investment, number of older and younger siblings, and parental characteristics such as education, race, and labor market skills. In this extension, gender is also included as a parental characteristic. Thus, the production function is still denoted by $M\left(x^{\prime} \mid z_{T+1}\right)$, where $z_{T+1}$ represents the state variables at the end of the parents' life cycle, $T$.

In the household, the total per-period expenditures cannot exceed the combined income of the spouses. The budget constraint for the household is given by

$$
w_{t} \geq c_{t}+\alpha_{N c}\left(z_{t}\right)\left(N_{t}+b_{t}\right) w_{t}\left(z_{t}, h_{t}\right) .
$$

The right-hand side of equation (36) represents expenditures on personal consumption of the parents, $c_{t}$, and on children. Parents pay for the children living in their household, regardless of the biological relationship, and do not transfer money to any biological children living outside the household.

As in the single-agent model, we can eliminate the continuous choice in the lifetime utility problem so that households face a purely discrete choice problem. Recall that the budget constraint for the household, assuming no borrowing or saving, is

$$
w_{t}\left(z_{t}, h_{t}\right)-\alpha_{N}\left(z_{t}\right)\left(N_{t}+b_{t}\right) w_{t}\left(z_{t}, h_{t}\right)=c_{t},
$$

and, as in the single-agent problem, we may substitute for consumption in $u_{2}$ and obtain the following household utility function:

$$
u_{k t}\left(z_{t}\right)=\theta_{k}\left(z_{t}\right)+u_{t}\left[w_{t}\left(z_{t}, h_{t}\right)\left(1-\alpha_{N}\left(z_{t}\right)\left(N_{t}+b_{t}\right)\right), z_{t}\right] .
$$

$\theta_{k}\left(z_{t}\right)$ is the explicit functional form we assumed for the $u_{1 k t}\left(z_{t}\right)$ in equation (8). In this formulation, each discrete choice $k$ corresponds to a utility level characterized by the parameter $\theta_{k}\left(z_{t}\right)$.

For notational simplicity, let $x_{f} \in\{f\}_{f=1}^{F}, x_{m} \in\{m\}_{m=1}^{M}$, and $P_{f m}$ be the probability that a type- $f$ female marries a type- $m$ male at age zero. We can then define the expected lifetime utility for a type- $(f, m)$ household at age zero, excluding the dynastic component, as

$$
U_{T}(f, m)=E_{0}\left[\sum_{t=0}^{T} \beta^{t} \sum_{k=0}^{K} I_{k t}^{0}\left\{u_{k t}\left(z_{t}\right)+\varepsilon_{k t}\right\}\right],
$$

and the expected lifetime utility for a type- $(f, m)$ household at age zero as

$$
U(f, m)=U_{T}(f, m)+\beta^{T} \lambda E_{0}\left[N^{-\nu} \sum_{n=1}^{N} \sum_{f^{\prime}=1}^{F} \sum_{m^{\prime}=1}^{M} P_{f^{\prime} m^{\prime}} U_{n}\left(f^{\prime}, m^{\prime}\right) \mid f, m\right] .
$$


As in the single individual version of the model, we can define the expected present discounted value of the lifetime utility of the household at any period $t$ as

$$
\begin{aligned}
V\left(z_{t}, \varepsilon_{t}\right)= & \max _{I} E_{I}\left(\sum_{s=t+1}^{T} \beta^{s-t} \sum_{k=0}^{K} I_{k s}\left[u_{k s}\left(z_{s}\right)+\varepsilon_{k s}\right]\right. \\
& \left.+\beta^{T-s} \lambda N^{-\nu} \sum_{n=1}^{N} \sum_{f^{\prime}=1}^{F} \sum_{m^{\prime}=1}^{M} P_{f^{\prime} m^{\prime}} U_{n}\left(f^{\prime}, m^{\prime}\right) \mid z_{t}, \varepsilon_{t}\right) .
\end{aligned}
$$

This can be written recursively as

$$
\left.V\left(z_{t}, \varepsilon_{t}\right)=\sum_{k=0}^{K} I_{k t}^{o}\left(z_{t}, \varepsilon_{t}\right)\left[u_{k t}\left(z_{t}\right)+\varepsilon_{k t}\right]+\beta \sum_{z^{\prime}} \int V\left(z^{\prime}, \varepsilon\right) f_{\varepsilon}(\varepsilon) d \varepsilon F\left(z^{\prime} \mid z_{t}, I_{k t}^{o}=1\right)\right],
$$

where $f_{\varepsilon}(\varepsilon)$ is the continuously differentiable density of $F_{\varepsilon}\left(\varepsilon_{0 t}, \ldots, \varepsilon_{17 t}\right), F\left(z^{\prime} \mid z_{t}, I_{k t}=1\right)$ is a transition function for state variables conditional on choice $k$, and $I_{k t}^{o}\left(z_{t}, \varepsilon_{t}\right)$ is the optimal household decision rule. Similar to equation (13), we can define the conditional choice household probability as $p_{k}\left(z_{t}\right)=E\left[I_{k t}^{o}=1 \mid z_{t}\right]$ and the ex ante value function as

$$
V\left(z_{t}\right)=\sum_{k=0}^{K} p_{k}\left(z_{t}\right)\left[u_{k t}\left(z_{t}\right)+E_{\varepsilon}\left[\varepsilon_{k t} \mid I_{k t}=1, z_{t}\right]+\beta \sum_{z^{\prime}} V\left(z^{\prime}\right) F\left(z^{\prime} \mid z_{t}, I_{k t}=1\right)\right] .
$$

The rest of the estimation carries through as in the single individual case.

The addition of the two household members to the model captures important issues of the degree of specialization in housework and labor market work in households with different composition of education levels between it members. The importance of which spouse spends time with the children (and the amount of time) depends on the production function of the education of children and whether the time of spouses are complements or substitutes. Furthermore, we capture patterns of assortative mating that may amplify the persistence of income across generations relative to a more random matching pattern. Since in our model there is a potential correlation of the cost of transfers to children (time input) with both parents' characteristics, assortative mating patterns imply that if children of more educated parents are more likely to be more educated, they are also more likely to have a more educated spouse, which increases the family resources and their children's educational outcomes.

\section{EMPIRICAL APPLICATION}

To illustrate the estimation method, we estimate the unitary household model developed in the previous section and use it to analyze the effect of Nature versus Nurture on intergenerational mobility. We estimate the model using a dataset compiled from the Panel Study of Income Dynamics (PSID). The PSID provides a large panel of matched data on individuals' labor market hours, earnings, housework hours, marriage, and childbirth histories for overlapping cohorts and generations. 
TABLE 2. Summary statistics for full sample.

\begin{tabular}{|c|c|c|c|c|c|c|}
\hline \multirow[b]{3}{*}{ Variable } & \multirow{2}{*}{\multicolumn{2}{|c|}{$\frac{\text { Full sample }}{(1)}$}} & \multirow{2}{*}{\multicolumn{2}{|c|}{$\frac{\text { Parents }}{(2)}$}} & \multirow{2}{*}{\multicolumn{2}{|c|}{$\begin{array}{c}\text { Children } \\
(3)\end{array}$}} \\
\hline & & & & & & \\
\hline & $N$ & Mean & $N$ & Mean & $N$ & Mean \\
\hline Female & 115,280 & 0.545 & 86,302 & 0.552 & 28,978 & 0.522 \\
\hline Black & 115,280 & 0.223 & 86,302 & 0.202 & 28,978 & 0.286 \\
\hline Married & 115,280 & 0.381 & 86,302 & 0.465 & 28,978 & 0.131 \\
\hline Age (yr) & 115,280 & $\begin{array}{l}26.155 \\
(7.699)\end{array}$ & 86,302 & $\begin{array}{c}27.968 \\
(7.872)\end{array}$ & 28,978 & $\begin{array}{l}20.756 \\
(3.511)\end{array}$ \\
\hline Education (years completed) & 115,280 & $\begin{array}{l}13.438 \\
(2.103)\end{array}$ & 86,302 & $\begin{array}{l}13.516 \\
(2.138)\end{array}$ & 28,978 & $\begin{array}{l}13.209 \\
(1.981)\end{array}$ \\
\hline No. of children & 115,280 & $\begin{array}{c}0.616 \\
(0.961)\end{array}$ & 86,302 & $\begin{array}{c}0.766 \\
(1.028)\end{array}$ & 28,978 & $\begin{array}{c}0.167 \\
(0.507)\end{array}$ \\
\hline Annual labor income (\$US 2005) & 114,871 & $\begin{array}{c}16,115 \\
(24,622)\end{array}$ & 86,137 & $\begin{array}{c}19,552 \\
(26,273)\end{array}$ & 28,734 & $\begin{array}{c}5811 \\
(14,591)\end{array}$ \\
\hline Annual labor market hours & 114,899 & $\begin{array}{c}915 \\
(1041)\end{array}$ & 86,185 & $\begin{array}{c}1078 \\
(1051)\end{array}$ & 28,714 & $\begin{array}{c}424 \\
(841)\end{array}$ \\
\hline Annual housework hours & 66,573 & $\begin{array}{c}714 \\
(578)\end{array}$ & 58,564 & $\begin{array}{c}724 \\
(585)\end{array}$ & 8009 & $\begin{array}{c}641 \\
(524)\end{array}$ \\
\hline Annual time spent on children (hr) & 115,249 & $\begin{array}{c}191 \\
(432)\end{array}$ & 86,275 & $\begin{array}{c}234 \\
(468)\end{array}$ & 28,974 & $\begin{array}{c}63.584 \\
(259)\end{array}$ \\
\hline Number of individuals & 12,318 & & 6813 & & 5505 & \\
\hline
\end{tabular}

Note: Standard deviations are listed in parentheses. Data are from the Family-Individual File of the Michigan Panel Study of Income Dynamics (PSID) and include individuals surveyed between 1968 and 1997. Column (1) contains the summary statistics for the full sample; column (2) contains the summary statistics for the parents generation; column (3) contains the summary statistics of the offspring of the parents in column (2). There are fewer observations for annual housework hours than time spent on children because single individuals with no children are coded as missing for housework hours but by definition are set to 0 for time spent on children.

Table 2 presents the summary statistics for our sample. Column (1) summarizes the overall sample, Column (2) shows data only for parents, and Column (3) summarizes data of their children. The first generation is on average seven years older than the second generation. As a consequence, a higher proportion are married in the first generation. The male-to-female ratio is similar across generations (about 55 percent female), and this ratio is higher in our sample than in the general population because females are more likely to maintain responsibility for children in cases of divorce. Our sample contains a higher proportion of blacks than the general population, which is consistent with PSID survey procedures, and the second generation has an even higher proportion of blacks than the first generation (about 29 percent in the second and 20 percent in the first generation) because of higher fertility rates among blacks in our sample. There are no significant differences across generations in completed years of education. The second generation in our sample has a lower average age than the first generation, so the second generation also has a lower marriage rate and a lower average number of children, annual labor income, labor market hours, housework hours, and mean time spent with children. Our second-generation sample spans the same age range, 17 to 55 , as the first sample. For the estimation, we retain only married households and include the married individuals as of age 25 with all the individual years of observations whenever the 
family is intact up to age 40. Further, to account for the time and monetary investments during the early years of the child's life after birth, we exclude individuals who already have a child by age 25 .

\subsection{Empirical implementation}

This section describes the choice set specifications and functional forms of the model that we estimate. We assume that all individuals enter the first period of the life cycle married. That is, they transition into a married household immediately after becoming adults. When individuals transition into a married household, their spouses' characteristics are drawn from the known matching function $G\left(x_{-\sigma} \mid x_{\sigma}\right)$. The matching function depends on the individual's state variables-for example, it separately captures past actions that affect labor market experience on the spouse's characteristics.

We set the number of an adult's periods in each generation to $T=30$ and measure the individual's age where $t=0$ is age 25 because at this age most individuals would have completed their education and started their family. As discussed earlier, we assume that parents receive utility from adult children, whose educational outcome is revealed at the last period of their life regardless of the birth date of the children. This assumption is similar to the Barro-Becker assumptions. We avoid situations where the outcome of an older child is revealed while parents make fertility and time investment decisions to ensure that (i) these decisions are not affected by adult children outcomes and (ii) adult children's behavior and choices do not affect investment in children and fertility of the parents, in which case solutions to the problems are significantly more complicated and it is not clear whether a solution exists.

The three levels of labor supply correspond to working 40 hours a week; individuals working fewer than 3 hours per week are classified as not working, individuals working between 3 and 20 hours per week are classified as working part-time, while individuals working more than 20 hours per week are classified as working full-time. There are three levels of parental time spent with children corresponding to no time, low time, and high time. To control for the fact that females spend significantly more time with children than males, we use a gender-specific categorization. We use the 50th percentile of the distribution of parental time spent with children as the threshold for low versus high parental time with children, and the third category is zero time with children. This classification is done separately for males and females. Finally, birth is a binary variable; it equals one if the mother gives birth in that year and zero otherwise. Therefore, the household choices are a combination of labor supply and time with children for males and females in the household plus the birth decision.

Labor market earnings. An individual's earnings depend on the subset of his or her characteristics, $z_{\sigma t}$. These include age, age squared, and dummy variables indicating whether the individual has completed high school, some college, or college (or more) education interacted with age, respectively; the omitted category is less than high school. Let $\eta_{\sigma}$ be the individual-specific ability, which is assumed to be correlated with the individual-specific time-invariant observed characteristics. Earnings are assumed to be 
the marginal productivity of workers and are assumed to be exogenous, linearly additive, and separable across individuals in the economy. The earnings equations are given by

$$
w_{\sigma t}=\exp \left(\delta_{0 \sigma} z_{\sigma t}+\sum_{s=0}^{\rho} \delta_{\sigma, s}^{p t} \sum_{k_{t-s} \in \mathcal{H}_{P \sigma}} I_{k_{t-s} \sigma}+\sum_{s=1}^{\rho} \delta_{\sigma, s}^{f t} \sum_{k_{t-s} \in \mathcal{H}_{F \sigma}} I_{k_{t-s} \sigma}+\eta_{\sigma}\right),
$$

where $\mathcal{H}_{P \sigma}$ and $\mathcal{H}_{F \sigma}$ are the set of choices for part-time and full-time work, respectively. Therefore, the earnings equation depends on experience accumulated while working part-time or full-time and the current level of labor supply. Thus, $\delta_{\sigma, s}^{p t}$ and $\delta_{\sigma, s}^{f t}$ capture the depreciation of the value of human capital accumulated while working part-time or full time, respectively. In the estimation, we assume $\rho=4$ given that the effect of experience with higher lags is insignificant (Gayle and Golan (2012), Gayle and Miller (2004)).

Production function of children. We assume that race is transmitted automatically to children and rule out interracial marriages and fertility. This is done because of insufficient interracial births in our sample to study this problem. Therefore, parental home hours when the child is young affect the future educational outcome of the child, which is denoted by $E d_{\sigma}^{\prime}, 22$ and innate ability, $\eta_{\sigma}^{\prime}$, both of which affect the child's earnings (see equation (43)).The state vector for the child in the first period of the life cycle is determined by the intergenerational state transition function $M\left(x^{\prime} \mid z_{T+1}\right)$; specifically, we assume that

$$
M\left(x^{\prime} \mid z_{T+1}\right)=\left[\operatorname{Pr}\left(\eta_{\sigma}^{\prime} \mid E d_{\sigma}^{\prime}\right), 1\right] \operatorname{Pr}\left(E d_{\sigma}^{\prime} \mid z_{T+1}\right) .
$$

Thus, we assume that the parental inputs and characteristics (parental education and fixed effects) determine educational outcomes according to the probability distribution $\operatorname{Pr}\left(E d_{\sigma}^{\prime} \mid z_{T+1}\right)$. In our empirical specification, the state vector of inputs, $z_{T+1}$, contains the parental characteristics, the cumulative investment variables (low time and high time with children) of each parent up to period $T$, the permanent income of each parent, and the number of a child's siblings. In the data, we observe only total time devoted to children each period; thus, we assign each child age 5 or younger in the household the average time investment, assuming all young children in the household receive the same time input. Parental characteristics include the education of the father and mother, their individual-specific effects, and race. Once the education level is determined, it is assumed that the ability $\eta_{\sigma}^{\prime}$ is determined according to the probability distribution $\operatorname{Pr}\left(\eta_{\sigma}^{\prime} \mid E d_{\sigma}^{\prime}\right)$. The above form of the transition allows us to estimate the equations separately for the production function of children given as the first two probabilities and the marriage market matching given as the last term.

Contemporaneous utility. We assume that the per-period utility from consumption is linear; therefore, equation (38), the utility from consumption and children (after substituting the budget constraint), becomes

$$
u_{k t}\left(z_{t}\right)=\theta_{k}\left(z_{t}\right)+\alpha w_{t}\left(z_{t}, h_{t}\right)-\alpha \alpha_{N}\left(z_{t}\right)\left(N_{t}+b_{t}\right),
$$

\footnotetext{
${ }^{22}$ Level of education, $E d_{\sigma}$, is a discrete random variable in the model where it can take 4 different values: less than high school (LHS), high school (HS), some college (SC), and college (COL).
} 
where $\theta_{k}\left(z_{t}\right)$ are the coefficients associated with each combination of time allocation choice, thus capturing the differences in the value of nonpecuniary benefits/costs associated with the different activities. The vector of decisions includes birth; thus, we allow the utility associated with different time allocations to depend on whether or not there is a birth. As discussed earlier, this utility captures not only the level of leisure but also the nonpecuniary costs/benefits associated with the different activities. For example, we do not rule out that time spent with children may be valued and that the nonpecuniary costs/benefits depend on birth events and levels of labor supply.

We assume no borrowing and saving, one consumption good with price normalized to 1, and risk neutrality. The first term represents the utility from a parent's own consumption. The second term, however, represents the net utility/costs from having young children in the household. In general, given our assumptions, we can use a budget constraint to derive the coefficients on income and number of children and a separate, nonpecuniary utility from children and monetary costs. However, since we do not have data on consumption or expenditures on children, the coefficients on the number of children also capture nonpecuniary utility from children and cannot be identified separately from the monetary costs of raising children. The interaction of income with the number of children and education captures differences in the costs of raising children by the socioeconomic status of the parents. By assuming a linear utility function, we abstract from risk aversion and insurance considerations that may affect investment in children, fertility, as well as the labor supply. For families, we ignore the insurance aspects of marriage and divorce. While these issues are potentially important, we abstract from them and focus on transmission of human capital. The no borrowing and savings assumption is extreme and allows us to test (i) whether income is important in the production function of education of children and (ii) whether the timing of income is important.

\section{EMPIRICAL RESUlts}

This section presents results of estimation and analysis of the structural model. First, we present estimates from Step 1 of our estimation procedure. Second, we present estimates from Step 2 of the estimation, which is estimated using the Hotz et al. (1994) extension of the Hotz and Miller (1993) estimator. ${ }^{23}$ Third, we present results that assess how well our model fits the data. Finally, we present counterfactual simulations that investigate the role of the automatic transmission of education across generations (Nature) on integenerational mobility at bottom of the income distribution.

\subsection{First-stage estimation}

The first-stage estimation include estimates of the earnings equation, the unobserved skills function, the intergenerational education production function, and the marriage

\footnotetext{
${ }^{23}$ We use the Hotz et al. (1994) estimator instead of the original Hotz and Miller (1993) estimator because the forward simulation used in the former significantly reduces the computational burden involved in computing the life-cycle component of the dynastic model.
} 
assignment functions. All these functions are fundamental parameters of our model and are estimated outside the estimation of the preferences, discount factors, and the net costs of raising children. The first-stage estimates also include equilibrium objects such as the CCPs. Below we present estimates on the main earnings equation, the unobserved skills function, and the intergenerational education production function. The estimates of the marriage assignment functions and the CCPs are included in the Supplementary Material (Gayle, Golan, and Soytas (2018)).

TABLE 3. Estimates of earnings equation: Dependent variable: Log of yearly earnings.

\begin{tabular}{|c|c|c|c|c|c|}
\hline Variable & Estimate & Variable & Estimate & Variable & Estimate \\
\hline \multicolumn{2}{|c|}{ Demographic Variables } & & & \multicolumn{2}{|c|}{ Fixed Effect } \\
\hline Age squared & $\begin{array}{l}-4.0 \mathrm{e}-4 \\
(1.0 \mathrm{e}-5)\end{array}$ & Female $\times$ Full-time work & $\begin{array}{l}-0.125 \\
(0.010)\end{array}$ & Black & $\begin{array}{l}-0.154 \\
(0.009)\end{array}$ \\
\hline Age $\times$ LHS & $\begin{array}{c}0.037 \\
(0.002)\end{array}$ & Female $\times$ Full-time work $(t-1)$ & $\begin{array}{c}0.110 \\
(0.010)\end{array}$ & Female & $\begin{array}{l}-0.484 \\
(0.007)\end{array}$ \\
\hline Age $\times$ HS & $\begin{array}{c}0.041 \\
(0.001)\end{array}$ & Female $\times$ Full-time work $(t-2)$ & $\begin{array}{c}0.025 \\
(0.010)\end{array}$ & HS & $\begin{array}{c}0.136 \\
(0.005)\end{array}$ \\
\hline Age $\times$ SC & $\begin{array}{c}0.050 \\
(0.001)\end{array}$ & Female $\times$ Full-time work $(t-3)$ & $\begin{array}{c}0.010 \\
(0.010)\end{array}$ & SC & $\begin{array}{c}0.122 \\
(0.006)\end{array}$ \\
\hline Age $\times$ COL & $\begin{array}{c}0.096 \\
(0.001)\end{array}$ & Female $\times$ Full-time work $(t-4)$ & $\begin{array}{c}0.013 \\
(0.010)\end{array}$ & COL & $\begin{array}{c}0.044 \\
(0.006)\end{array}$ \\
\hline \multicolumn{2}{|c|}{ Current and Lags of Participation } & Female $\times$ Part-time work $(t-1)$ & 0.150 & Black $\times$ HS & -0.029 \\
\hline Full-time work & $\begin{array}{c}0.938 \\
(0.010)\end{array}$ & Female $\times$ Part-time work $(t-2)$ & $\begin{array}{c}(0.010) \\
0.060\end{array}$ & Black $\times$ SC & $\begin{array}{c}(0.010) \\
0.033\end{array}$ \\
\hline Full-time work $(t-1)$ & $\begin{array}{c}0.160 \\
(0.009)\end{array}$ & Female $\times$ Part-time work $(t-3)$ & $\begin{array}{c}(0.010) \\
0.040\end{array}$ & Black $\times$ COL & $\begin{array}{c}(0.008) \\
0.001\end{array}$ \\
\hline Full-time work $(t-2)$ & $\begin{array}{c}0.044 \\
(0.010)\end{array}$ & Female $\times$ Part-time work $(t-4)$ & $\begin{array}{l}(0.010) \\
-0.002\end{array}$ & Female $\times$ HS & $\begin{array}{l}(0.011) \\
-0.054\end{array}$ \\
\hline Full-time work $(t-3)$ & $\begin{array}{c}0.025 \\
(0.010)\end{array}$ & Individual specific effects & $\begin{array}{l}(0.010) \\
\text { Yes }\end{array}$ & Female $\times$ SC & $\begin{array}{c}(0.008) \\
0.049\end{array}$ \\
\hline Full-time work $(t-4)$ & $\begin{array}{c}0.040 \\
(0.010)\end{array}$ & & & Female $\times$ COL & $\begin{array}{c}(0.006) \\
0.038\end{array}$ \\
\hline Part-time work $(t-1)$ & $\begin{array}{l}-0.087 \\
(0.010)\end{array}$ & & & Constant & $\begin{array}{c}(0.007) \\
0.167\end{array}$ \\
\hline Part-time work $(t-2)$ & $\begin{array}{l}-0.077 \\
(0.010)\end{array}$ & & & & $(0.005)$ \\
\hline Part-time work $(t-3)$ & $\begin{array}{l}-0.070 \\
(0.010)\end{array}$ & & & & \\
\hline Part-time work $(t-4)$ & $\begin{array}{l}-0.010 \\
(0.010)\end{array}$ & $\begin{array}{l}\text { Hausman Statistics } \\
\text { Hausman } p \text {-value }\end{array}$ & $\begin{array}{l}2296 \\
0.000\end{array}$ & & \\
\hline No. of Observations & & & 134,007 & & \\
\hline No. of Individuals & & & 14,018 & & \\
\hline $\mathrm{R}^{2}$ & & & 0.44 & & 0.278 \\
\hline
\end{tabular}

Note: Standard errors are listed in parentheses. LHS indicates completed education of less than high school; HS indicates completed education of high school but not college; SC indicates completed education of some college but not a graduate; COL indicates completed education of at least a college degree. 
Earnings equation and unobserved skills. Table 3 presents the estimates of the earnings equation and the function of unobserved (to the econometrician) individual skill (see also Gayle, Golan, and Soytas (2014)). The top panel of the first column shows that the age-earnings profile is significantly steeper for higher levels of completed education; the slope of the age-log-earnings profile for a college graduate is about three times that of an individual with less than a high school education. However, the largest gap is for college graduates; the age-log-earnings profile for a college graduate is about twice that of an individual with only some college. These results confirm that there are significant returns to parental time investment in children in terms of the labor market because parental investment significantly increases the likelihood of higher education outcomes, which significantly increases lifetime labor market earnings.

The bottom panel of the first column and the second column of Table 3 show that male full-time workers earn 2.6 times more than part-time male workers and female full-time workers earn 2.3 times more than females part-time workers (see also Gayle, Golan, and Soytas (2014)). It also shows that there are significant returns to past fulltime employment for both genders; however, females have higher returns to full-time labor market experience than males. The same is not true for part-time labor market experience; males' earnings are lower if they worked part-time in the past, while there are positive returns to the most recent female part-time experience. However, part-time experiences 2 and 3 years in the past are associated with lower earnings for females; these rates of earnings reduction are, however, lower than those for males. These results are similar to those in Gayle and Golan (2012) and perhaps reflect statistical discrimination in the labor market in which past labor market history affects employers' beliefs about workers' labor market attachment in the presence of hiring costs. ${ }^{24}$ These results imply there are significant costs in the labor market in terms of the loss of human capital from spending time with children, if spending more time with children comes at the expense of working more in the labor market. These costs may be smaller for females than males because part-time work reduces compensation less for females than for males. If a female works part-time for 3 years, for example, she loses significantly less human capital than a male working part-time for 3 years instead of full-time. This difference may give rise to females specializing in child care; this specialization comes from the labor market and production function of a child's outcome, as is the current wisdom.

The unobserved skill (to the econometrician) is assumed to be a parametric function of the strictly exogenous time-invariant components of the individual variables. This assumption is used in other papers (e.g., MaCurdy (1981), Chamberlain (1986), Nijman and Verbeek (1992), Zabel (1992), Newey (1994), Altug and Miller (1998), and Gayle and Viauroux (2007)). It allows us to introduce unobserved heterogeneity to the model while still maintaining the assumption on the discreteness of the state space of the dynamic programming problem needed to estimate the structural parameters from the dynastic model. Also because the unobserved skill is estimated in the first step, and hence is data in the subsequence steps this does not introduce the standard initial condition problem. The Hausman test statistic shows that we cannot reject this correlated fixed effect

\footnotetext{
${ }^{24}$ These results are also consistent with part-time jobs differing from full-time jobs for males more than for females.
} 
TABLE 4. Three-stage least squares estimation of the education production function.

\begin{tabular}{|c|c|c|c|}
\hline Variable & High School & Some College & College \\
\hline High school father & $\begin{array}{c}0.063 \\
(0.032)\end{array}$ & $\begin{array}{c}0.003 \\
(0.052)\end{array}$ & $\begin{array}{c}-0.002 \\
(0.0435)\end{array}$ \\
\hline Some college father & $\begin{array}{c}0.055 \\
(0.023)\end{array}$ & $\begin{array}{c}0.132 \\
(0.038)\end{array}$ & $\begin{array}{c}0.055 \\
(0.031)\end{array}$ \\
\hline College father & $\begin{array}{l}-0.044 \\
(0.032)\end{array}$ & $\begin{array}{c}0.008 \\
(0.051)\end{array}$ & $\begin{array}{c}0.120 \\
(0.042)\end{array}$ \\
\hline High school mother & $\begin{array}{c}0.089 \\
(0.040)\end{array}$ & $\begin{array}{c}0.081 \\
(0.065)\end{array}$ & $\begin{array}{l}-0.019 \\
(0.052)\end{array}$ \\
\hline Some college mother & $\begin{array}{c}0.007 \\
(0.030)\end{array}$ & $\begin{array}{l}-0.041 \\
(0.049)\end{array}$ & $\begin{array}{c}0.017 \\
(0.039)\end{array}$ \\
\hline College mother & $\begin{array}{c}0.083 \\
(0.036)\end{array}$ & $\begin{array}{c}0.120 \\
(0.057)\end{array}$ & $\begin{array}{c}0.040 \\
(0.047)\end{array}$ \\
\hline Mother's time & $\begin{array}{c}-0.014 \\
(0.021)\end{array}$ & $\begin{array}{c}0.080 \\
(0.034)\end{array}$ & $\begin{array}{c}0.069 \\
(0.027)\end{array}$ \\
\hline Father's time & $\begin{array}{c}0.031 \\
(0.019)\end{array}$ & $\begin{array}{c}0.100 \\
(0.029)\end{array}$ & $\begin{array}{c}0.026 \\
(0.025)\end{array}$ \\
\hline Mother's labor income & $\begin{array}{l}-0.025 \\
(0.009)\end{array}$ & $\begin{array}{l}-0.013 \\
(0.014)\end{array}$ & $\begin{array}{c}0.005 \\
(0.011)\end{array}$ \\
\hline Father's Labor Income & $\begin{array}{c}0.001 \\
(0.003)\end{array}$ & $\begin{array}{c}0.001 \\
(0.004)\end{array}$ & $\begin{array}{c}0.002 \\
(0.003)\end{array}$ \\
\hline Female & $\begin{array}{l}-0.002 \\
(0.017)\end{array}$ & $\begin{array}{c}0.135 \\
(0.028)\end{array}$ & $\begin{array}{c}0.085 \\
(0.022)\end{array}$ \\
\hline Black & $\begin{array}{c}0.020 \\
(0.039)\end{array}$ & $\begin{array}{c}0.082 \\
(0.063)\end{array}$ & $\begin{array}{c}0.043 \\
(0.051)\end{array}$ \\
\hline No. of siblings under age 3 & $\begin{array}{l}-0.014 \\
(0.017)\end{array}$ & $\begin{array}{l}-0.107 \\
(0.027)\end{array}$ & $\begin{array}{l}-0.043 \\
(0.022)\end{array}$ \\
\hline No. of siblings between ages 3 and 6 & $\begin{array}{l}-0.029 \\
(0.019)\end{array}$ & $\begin{array}{l}-0.047 \\
(0.030)\end{array}$ & $\begin{array}{l}-0.012 \\
(0.025)\end{array}$ \\
\hline Constant & $\begin{array}{c}0.855 \\
(0.108)\end{array}$ & $\begin{array}{l}-0.231 \\
(0.172)\end{array}$ & $\begin{array}{l}-0.359 \\
(0.140)\end{array}$ \\
\hline Observations & 1335 & 1335 & 1335 \\
\hline
\end{tabular}

Note: Standard errors are listed in parentheses; the excluded class is less than high school. Data are from the FamilyIndividual File of the Michigan Panel Study of Income Dynamics (PSID), and include individuals surveyed between 1968 and 1997. Instruments: Mother's and father's labor market hours over the child's first 8 years of life, linear and quadratic terms of mother's and father's age when the child was 5 years old.

specification. Column (3) of Table 4 presents the estimate of skills as a function of unobserved characteristics; it shows that blacks and females have lower unobserved skills than whites and males. This could capture labor market discrimination. Education increases the level of skills but it increases at a decreasing rate with the level of completed education. The rates of increase for blacks and females with some college and a college degree are higher than those of their white and male counterparts. This pattern is reversed for blacks and females with a high school diploma. Notice that skills are another transmission mechanism through which parental time investment affects labor market earnings in addition to education.

Intergenerational education production function. A well-known problem with the estimation of production functions is the simultaneity of the inputs (time spent with chil- 
dren and income). As is clear from the structural model, the intergenerational education production function suffers from a similar problem. However, because the output of the intergenerational education production (i.e., completed education level) is determined across generations while the inputs, such as parental time investment, are determined over the life cycle of each generation, we can treat these inputs as predetermined and use instruments from within the system to estimate the production function.

Table 4 presents results of a three-stage least squares estimation of the system of individual educational outcomes; the estimates of the two other stages are available in the Supplementary Material (Gayle, Golan, and Soytas (2018)). The system includes the linear probabilities of the education outcomes, $\operatorname{Pr}\left(E d_{\sigma}^{\prime} \mid z_{T+1}\right)$, as well as the labor supply, income, and time spent with children equations. The estimation uses the mother's and father's labor market hours over the first 5 years of the child's life as well as linear and quadratic terms of the mother's and father's age on the child's fifth birthday as instruments. The estimation results show that controlling for all inputs, a child whose mother has a college education has a higher probability of obtaining at least some college education and a significantly lower probability of not graduating from high school relative to a child with a less educated mother; while the probability of graduating from college is also larger, it is not statistically significant. If a child's father, however, has some college or a college education, the child has a higher probability of graduating from college. This is consistent with the findings of Rios-Rull and Sanchez-Marcus (2002).

We measure parental time investment as the sum of the parental time investment over the first 5 years of the child's life. The total time investment (i.e., the sum of the per-period investment of the first 5 years of a child's life) is a variable that ranges between 0 and 10 because low yearly parental investment is coded as one and high yearly parental investment is code as two. The results in Table 5 show that while a mother's time investment significantly increases the probability of a child graduating from college or having some college, a father's time investment significantly increases the probability of the child graduating from high school or having some college. These estimates suggest that while a mother's time investment increases the probability of a high educational outcome, a father's time investment truncates low educational outcome. However, the time investment of both parents is productive in terms of their children's education outcomes. It is important to note that mothers' and fathers' hours spent with children are at different margins, with mothers spending significantly more hours than fathers. Thus, the magnitudes of the discrete levels of time investment of mothers and fathers are not directly comparable since low and high investment of time differs across genders.

\subsection{Second-stage estimation}

This section presents estimates of the intergenerational and intertemporal discount factors, the preference parameters, and child care cost parameters. Table 6 presents the discount factors. It shows that the intergenerational discount factor, $\lambda$, is 0.795 . This implies that in the second-to-last period of the parent's life, a parental valuation of their child's utility is $79.5 \%$ of their own utility. The estimated value is in the same range of values obtained in the literature calibrating dynastic model (Rios-Rull and SanchezMarcos (2002), Greenwood, Guner, and Knowles (2003)). However, these models do not 
TABLE 5. Structural estimates of discount factors and utility parameter.

\begin{tabular}{|c|c|c|c|c|}
\hline Variable & Estimates & Variable & & Estimates \\
\hline \multicolumn{2}{|l|}{ Discount factors } & \multicolumn{3}{|c|}{ Disutility/Utility of Choices } \\
\hline \multirow[t]{2}{*}{$\beta$} & 0.816 & Wife & Husband & \\
\hline & $(0.002)$ & \multicolumn{3}{|c|}{ Labor supply } \\
\hline$\lambda$ & $\begin{array}{c}0.795 \\
(0.200)\end{array}$ & No work & Part-time & $\begin{array}{l}-0.512 \\
(0.005)\end{array}$ \\
\hline$v$ & $\begin{array}{c}0.248 \\
(0.168)\end{array}$ & No work & Full-time & $\begin{array}{c}0.207 \\
(0.009)\end{array}$ \\
\hline \multicolumn{2}{|l|}{ Marginal Utility of Income } & Part-time & No work & -2.023 \\
\hline \multirow[t]{2}{*}{ Family labor income } & 0.480 & & & $(0.003)$ \\
\hline & $\begin{array}{l}(0.004) \\
-0.466\end{array}$ & Part-time & Part-time & $\begin{array}{l}-1.168 \\
(0.009)\end{array}$ \\
\hline Children $\times$ Family labor income & $(0.066)$ & Part-time & Full-time & -0.605 \\
\hline \multirow[t]{2}{*}{ Children $\times$ HS $\times$ Family labor income } & 1.216 & & & $(0.008)$ \\
\hline & $(0.065)$ & Full-time & No work & -0.408 \\
\hline \multirow[t]{2}{*}{ Children $\times$ SC $\times$ Family labor income } & 1.279 & & & $(0.007)$ \\
\hline & $(0.066)$ & Full-time & Part-time & -1.24532 \\
\hline \multirow[t]{2}{*}{ Children $\times$ COL $\times$ Family labor income } & 1.300 & & & $(0.011)$ \\
\hline & $(0.065)$ & Full-time & Full-time & 0.001 \\
\hline Children $\times$ HS spouse $\times$ Family labor income & $\begin{array}{l}-1.017 \\
(0.066)\end{array}$ & \multicolumn{3}{|c|}{ Time with children } \\
\hline Children $\times$ SC spouse $\times$ Family labor income & $\begin{array}{l}-0.995 \\
(0.066)\end{array}$ & Low & Medium & $\begin{array}{c}0.502 \\
(0.014)\end{array}$ \\
\hline Children $\times$ COL spouse $\times$ Family labor income & $\begin{array}{l}-0.992 \\
(0.066)\end{array}$ & Low & High & $\begin{array}{c}0.564 \\
(0.013)\end{array}$ \\
\hline \multirow[t]{7}{*}{ Children $\times$ Black $\times$ Family Labor Income } & $\begin{array}{l}-0.108 \\
(0.004)\end{array}$ & Medium & Low & $\begin{array}{l}-0.169 \\
(0.008)\end{array}$ \\
\hline & & Medium & Medium & $\begin{array}{c}0.129 \\
(0.010)\end{array}$ \\
\hline & & Medium & High & $\begin{array}{c}0.593 \\
(0.013)\end{array}$ \\
\hline & & High & Low & $\begin{array}{l}-0.364 \\
(0.007)\end{array}$ \\
\hline & & High & Medium & $\begin{array}{c}0.353 \\
(0.011)\end{array}$ \\
\hline & & High & High & $\begin{array}{l}-0.140 \\
(0.012)\end{array}$ \\
\hline & & Birth & & $\begin{array}{c}0.701 \\
(0.025)\end{array}$ \\
\hline
\end{tabular}

Note: Standard errors are listed in parentheses. LHS indicates completed education of less than high school; HS indicates completed education of high school but not college; SC indicates completed education of some college but not a graduate; COL indicates completed education of at least a college degree. The excluded choice is no work, no time with children, and no birth for both spouses.

include the life cycle. The estimated discount factor, $\beta$, is 0.81 . The discount factor is smaller than typical calibrated values; however, the few papers that have estimated it 


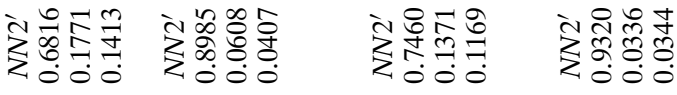

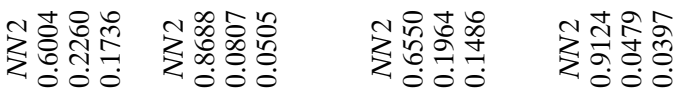

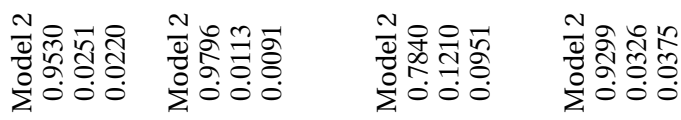

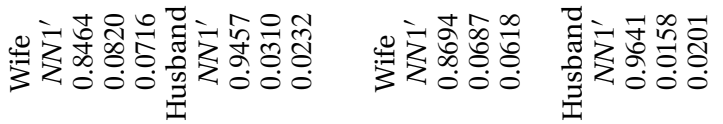

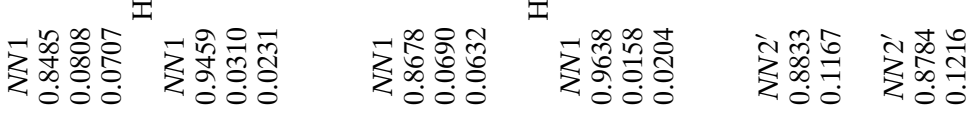

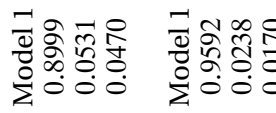

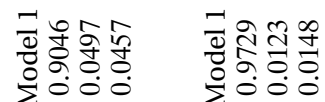

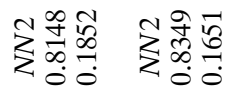

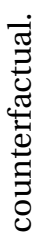

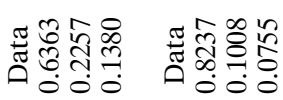

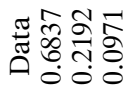

ஐ

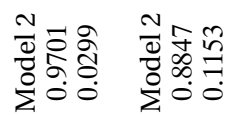

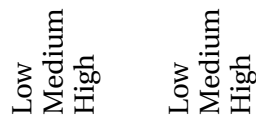

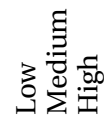

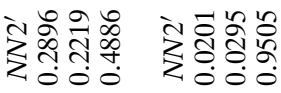

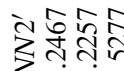

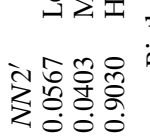

罗

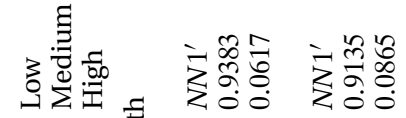

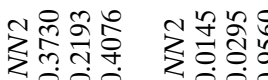

रू़่ तูก

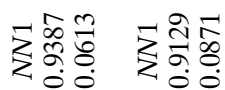

ㅇํㄹํํำ

ํํำ

之융.

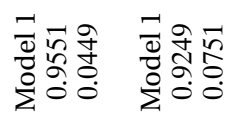

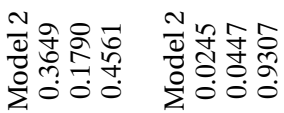

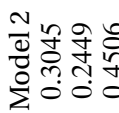

ำ 近0

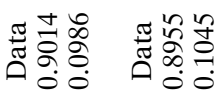

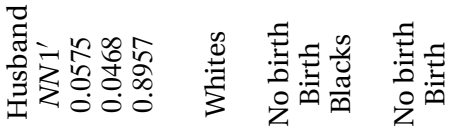

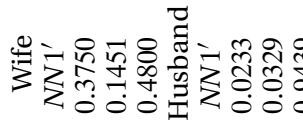

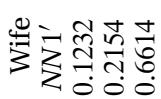

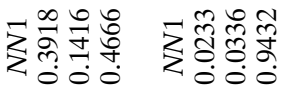

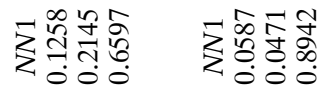

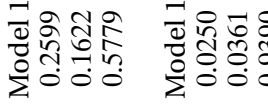

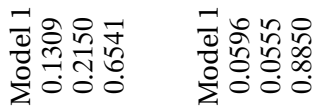

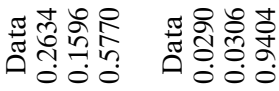

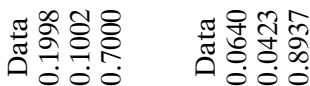

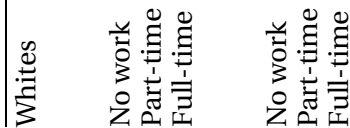

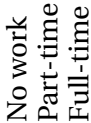

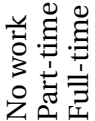

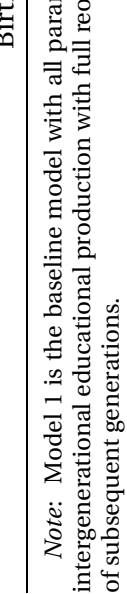


find similar values (e.g., Arcidiacono, Sieg, and Sloan (2007), find it to be 0.8). ${ }^{25}$ Lastly, the discount factor associated with the number children, $v$, is 0.25 which implies that the marginal increase in value from the second child is 0.68 and from the third child is 0.60 . Identification of the discounts factors are nontrivial in dynamic discrete models. Here, we have three discount factors to identify instead of one as in the standard discrete choice models. However, note that past home hours, when the children are young, affect only the transition functions and not the current utility, so we have the common exclusion restrictions used to identify dynamic discrete choice models (Magnac and Thesmar (2002), Fang and Wang (2015)). Then the identification of the intergenerational discounts factors follows by a direct application of the proof of Proposition 2 in Fang and Wang (2015) to our setting.

Table 5 also presents the marginal utility of income, which is positive and increasing with the number of children except for a household with a college graduate wife and a husband with at least a high school education. Also, a husband's education decreases the marginal utility of income for families with children. The marginal utility of income for families with children is also lower for black families.

The right panel of Table 5 presents our estimates of the disutility/utility from various combination of household choices. As is usual in discrete choice models, these are estimated relative to an outside choice, which is both spouses not (i) working, (ii) giving birth, or (iii) spending any time with young children. We also use an additive specification in which the costs of birth, work, and time with children are additively separable. First, every labor supply choice of the household carries with it a disutility relative to the reference choice except for households in which both spouses work full-time (which statistically is no different from disutility/utility reference) and when the wife does not work and the husband works full-time. In the data, if both spouses spend low time with children and there is no birth, then both spouses are equally likely to be observed working full-time than not working; hence the equal utility for both sets of choices. Second, there are no distinct patterns to utility from time with children; these estimates are highly nonlinear, perhaps reflecting that it is a mixture of leisure and disutility. However, giving birth provides a positive utility. This implies that, although parents get utility from the quality of their children, they also get some instantaneous utility from a birth.

\subsection{Model fit}

In this section, we first assess the ability of our model to reproduce the basic stylized facts by race, gender, and marital status. We assess how well our model predicts the choices of labor supply, home hours with young children, and birth. Our model is over identified and passes the standard over identifying restrictions J-test. In the estimation, the CCPs are targeted; in the model fit analysis, we simulate a sample of individuals and determine whether the individuals in our simulated sample behave like the individuals in our data. In some regards, this exercise is equivalent to a graphical summary of our model's over identification test.

\footnotetext{
${ }^{25} \mathrm{We}$ are not aware of dynastic models in which the time discount factor is estimated.
} 
Table 6 presents the model's fit. The model matches the labor supply patterns between gender and across race well. While it also matches the variation across race and gender for parental time with children, the levels are not similar in all cases. In examining the birth decisions, the model produces the differences in birth rates across households of different race, but it underpredicts the fecundity of whites by about a half. This lower birth rate is partly rationalized by the lower time with children predicted by the model. Nevertheless, our empirical model specification is very parsimonious: We do not include race, education, or marital status in the preference parameters for the disutility/utility of the different choices. In addition, the only unobserved heterogeneity is estimated from the earnings equations. Still, the model performs well in replicating the data based primarily on the economic interactions embodied in it.

\subsection{The effect of nature versus nurture on intergenerational mobility}

One of the major benefits of our approach is the ability to do full blown counterfactual analysis. An alternative approach which has been used in empirical structural models to incorporate intergenerational/altruistic concerns is to modify the standard dynamics structural estimation methods by introducing an approximation for the value parents place on their children's adults outcome as a function of some state variables, normally the educational outcome or test scores (see, e.g., Bernal (2008), Brown and Flinn (2011), and Del Boca, Flinn, and Wiswall (2013) among others). The main advantage of this alternate approach is that the estimation is easier and standard techniques in the literature can be used. The major disadvantage is that welfare/counterfactual analysis is subject to Lucas' critique. That is, in a counterfactual environment the value parents place on their children quality changes in two ways, the value of the state variables and the functional form of the mapping between the state variables and the utility derived from those state variables. The is made obvious by an examination of equations (18) and (20). This alternative approach does not allow the functional form of the mapping to change.

From equations (18) and (20), one can see that our framework can nested this alternative approach, since the approximation used in the alternative approach is equivalent to conducting a welfare/counterfactual analysis holding fixed the CCPs and transition used in the calculation of the value of a child. To illustrate the bias induced by ignoring the fact that the children themselves will reoptimize when we change the economic environment, we asked the counterfactual question of how much of the mobility across generations is due to the automatic transmission education across generations as opposed to differences in parent investment between parents of different educational background. To do this, we eliminate the automatic transition of education in production function. ${ }^{26}$ We report the results from two models. Model (1) is the model estimated in above. Model (2) is a model in which the discount factors ( $\beta$ and $\lambda$ ) are set to values commonly used in the literature $(\beta=0.90$ and $\lambda=0.95)$ and all other parameters estimated.

\footnotetext{
${ }^{26}$ Operationally, we set the effect on education in the intergenerational production function equal to that of a high school graduate irrespective of the mother's and father's education level.
} 


\section{Parents in the bottom $20 \%$ of income distribution and children above median of}

Income distribution

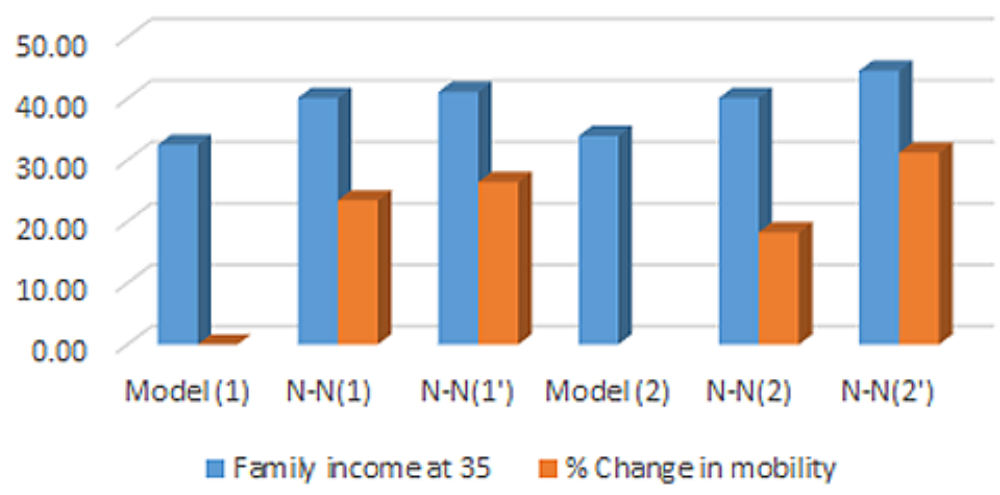

FIgURE 1. Counterfactuals and mobility. Note: Model 1 is the baseline model with all parameters estimated. Model 2 is the model with discount factors calibrated $(\beta=0.90, \lambda=0.95)$. $N N(i), i=1,2$ removes Nature from the intergenerational educational production with full re-optimization. $N N\left(i^{\prime}\right), i=1,2$ removes Nature from the intergenerational educational production but $D o$ Not allow for re-optimization of subsequent generations.

Table 6 presents the summary of labor supply, time investment, and birth rate by gender and race for the data, baseline models and counterfactual simulations. It shows that if we eliminate the portion of parental education that is transmitted automatically across generation then parents will reoptimize and change labor supply, time investment, and fertility behaviors. Therefore, a pure statistical decomposition would be inappropriate for answering the question of how much mobility would change if there were no automatic (Nature) transmission of education from parents to children. The columns $N N 1$ presents the counterfactual estimates of our model and $N N 1^{\prime}$ the estimation results of the approximated model; similarly, $N N 2$ presents the results of the counterfactual from our model with $(\beta=0.90$ and $\lambda=0.95)$ and $N N 2^{\prime}$ the results of the counterfactual of the approximated model. The columns $N N 1^{\prime}$ and $N N 2^{\prime}$ show that not taking into account that the all subsequent generations will also reoptimize induces significant bias with the bias being greater the larger the discount factors.

To obtain a number that summarize the impact on mobility, Figure 1 presents the probability that a children born in a family in the bottom 20 percent of the family income distribution will end up in a family with family income above the median of the next generation family income distribution. It shows that in the baseline model, that is, model 1, that only 30 percent of children born in the bottom 20 percent will end up with families earning above the median. However, if the automatic transition of education was eliminated that probability would increase by about 20 percent to about 40 percent. However, ignoring the re-optimization of subsequent generations, we overestimate the impact of eliminating the automatic transition of education across generations on mobility by about 25 percent. Model (2) shows the similar qualitative patterns but shows 
that the overestimate of the impact of "Nature" on mobility could be as high as 90 percent, which illustrate the gain from using the approach outline in this paper.

\section{Conclusion}

This paper provides a new representation of the value function for discrete choice dynastic models that partially overcomes the curse of dimensionality of dynastic models by exploiting properties of the stationary decision rules. The representation can be used in multistage CCP estimators to estimate a rich class of dynastic models including investment in children's human capital, monetary transfers, unitary households, endogenous fertility, and a life cycle within each generation. Under certain conditions, we show that the framework can also accommodate continuous choice variables. The paper extends methods used in the literature for the estimation of single-agent nondynastic models to the dynastic setting. The paper compares the performance of a multistage CCP estimator based on the new value function representation with a modified version of the full solution MLE using simulations and finds that the estimates are close to the nested fixed-point estimates as the sample increases but the computation time is reduced substantially.

The paper then provides an application of a unitary household model in which households choose labor supply, time with children, and fertility; human capital is transmitted across generations by monetary and time investments of the parents. We then used the estimate model to conduct counterfactual simulations, investigating the role of the automatic transmission of education across generations (Nature effect) in accounting for the intergenerational immobility at the bottom of the income distribution. We find that without the Nature effect in the intergenerational education production function mobility at the bottom of the income distribution would have been 20 percent higher. Finally, not accounting for the reoptimization of sequent generations in the model, as is done in the approach outlined in this paper, will overstate the effect of the Nature on mobility by between 20 and 90 percent.

\section{APPENDix}

Proof of Proposition 1. Recall the conditional value function in equation (14):

$$
v_{k}\left(z_{t}\right)=u_{k t}\left(z_{t}\right)+\beta \sum_{z_{t+1}} V\left(z_{t+1}\right) F\left(z_{t+1} \mid z_{t}, I_{k t}=1\right) .
$$

We begin by noting that

$$
\begin{aligned}
V\left(z_{t+1}\right)= & \sum_{s=0}^{17} p_{s}\left(z_{t+1}\right)\left[u_{s t+1}\left(z_{t+1}\right)\right. \\
& +E_{\varepsilon}\left(\varepsilon_{s t+1} \mid I_{s t+1}=1, z_{t+1}\right) \\
& \left.+\beta \sum_{z_{t+2}} V\left(z_{t+2}\right) F\left(z_{t+2} \mid z_{t+1}, I_{s t+1}=1\right)\right]
\end{aligned}
$$


Combining equations (46) and (47) give

$$
\begin{aligned}
v_{k}\left(z_{t}\right)= & u_{k t}\left(z_{t}\right)+\beta \sum_{z_{t+1}} \sum_{s=0}^{17} p_{s}\left(z_{t+1}\right)\left[u_{s t+1}\left(z_{t+1}\right)\right. \\
& \left.+E_{\varepsilon}\left(\varepsilon_{s t+1} \mid I_{s t+1}=1, z_{t+1}\right)\right] F\left(z_{t+1} \mid z_{t}, I_{k t}=1\right) \\
& +\beta^{2} \sum_{z_{t+1}} \sum_{s=0}^{17} p_{s}\left(z_{t+1}\right)\left[\sum_{z_{t+2}} V\left(z_{t+2}\right) F\left(z_{t+2} \mid z_{t+1}, I_{s t+1}=1\right)\right] F\left(z_{t+1} \mid z_{t}, I_{k t}=1\right) .
\end{aligned}
$$

Similarly,

$$
\begin{aligned}
V\left(z_{t+2}\right)= & \sum_{r=0}^{17} p_{r}\left(z_{t+2}\right)\left[u_{r t+2}\left(z_{t+2}\right)\right. \\
& +E_{\varepsilon}\left(\varepsilon_{r t+2} \mid I_{r t+2}=1, z_{t+2}\right) \\
& \left.+\beta \sum_{z+3} V\left(z_{t+3}\right) F\left(z_{t+3} \mid z_{t+2}, I_{r t+2}=1\right)\right] .
\end{aligned}
$$

Substituting equation (49) into equation (48) gives

$$
\begin{aligned}
v_{k}\left(z_{t}\right)= & u_{k t}\left(z_{t}\right)+\beta \sum_{z_{t+1}} \sum_{s=0}^{17} p_{s}\left(z_{t+1}\right)\left[u_{s t+1}\left(z_{t+1}\right)\right. \\
& \left.+E_{\varepsilon}\left(\varepsilon_{s t+1} \mid I_{s t+1}=1, z_{t+1}\right)\right] F\left(z_{t+1} \mid z_{t}, I_{k t}=1\right) \\
& +\beta^{2} \sum_{z_{t+1}} \sum_{s=0}^{17} p_{s}\left(z_{t+1}\right) \sum_{z_{t+2}} \sum_{r=0}^{17} p_{r}\left(z_{t+2}\right)\left[u_{r t+2}\left(z_{t+2}\right)\right. \\
& \left.+E_{\varepsilon}\left(\varepsilon_{r t+2} \mid I_{r t+2}=1, z_{t+2}\right)\right] \\
& \times F\left(z_{t+2} \mid z_{t+1}, I_{s t+1}=1\right) F\left(z_{t+1} \mid z_{t}, I_{k t}=1\right) \\
& +\beta^{3} \sum_{z_{t+1}} \sum_{s=0}^{17} p_{s}\left(z_{t+1}\right) \sum_{z_{t+2}} \sum_{r=0}^{17} p_{r}\left(z_{t+2}\right) \\
& \times \sum_{z+3} V\left(z_{t+3}\right) F\left(z_{t+3} \mid z_{t+2}, I_{r t+2}=1\right) \\
& \times F\left(z_{t+2} \mid z_{t+1}, I_{s t+1}=1\right) F\left(z_{t+1} \mid z_{t}, I_{k t}=1\right) .
\end{aligned}
$$

Without loss of generality (WLOG), we assume $t+3=T$; then

$$
V\left(z_{T}, \varepsilon_{T}\right)=\max _{I} E\left(\sum_{k=0}^{17} I_{k T}\left[u_{k T}\left(z_{T}\right)+\varepsilon_{k T}+\lambda N_{k}\left(z_{T}\right)^{-\nu} \sum_{n=1}^{N_{k}} \sum_{x_{n}} U_{g+1, n}\left(x_{n}\right)\right] \mid z_{T}, \varepsilon_{T}\right) .
$$


Now

$$
\begin{aligned}
V\left(z_{T}\right)= & \int V\left(z_{T}, \varepsilon_{T}\right) f_{\varepsilon}\left(\varepsilon_{T}\right) d \varepsilon_{T} \\
= & \int \max _{I} E\left(\sum _ { j = 0 } ^ { 1 7 } I _ { j T } \left[u_{j T}\left(z_{T}\right)+\varepsilon_{j T}\right.\right. \\
& \left.\left.+\lambda N_{j}\left(z_{T}\right)^{-\nu} \sum_{n=1}^{N_{j}} \sum_{x_{n}} U_{g+1, n}\left(x_{n}\right)\right] \mid z_{T}, \varepsilon_{T}\right) f_{\varepsilon}\left(\varepsilon_{T}\right) d \varepsilon_{T} \\
= & \sum_{j=0}^{17} p_{j}\left(z_{T}\right)\left[u_{k T}\left(z_{T}\right)+E_{\varepsilon}\left(\varepsilon_{j T} \mid z_{T}, I_{j T}=1\right)\right. \\
& \left.+\lambda N_{j}\left(z_{T}\right)^{-\nu} \sum_{n=1}^{N_{j}} \sum_{x_{n}} U_{g+1, n}\left(x_{n}\right) M\left(x_{n}^{\prime} \mid z_{T}, I_{j T}=1\right)\right] .
\end{aligned}
$$

We know from the value function representation that $U_{g+1, n}\left(x_{n}\right)=V\left(x_{n}\right)$; therefore,

$$
\begin{aligned}
V\left(z_{T}\right)= & \sum_{j=0}^{17} p_{j}\left(z_{T}\right)\left[u_{j T}\left(z_{T}\right)+E_{\varepsilon}\left(\varepsilon_{j T} \mid z_{T}, I_{j T}=1\right]\right. \\
& \left.+\lambda N_{j}\left(z_{T}\right)^{-\nu} \sum_{n=1}^{N_{j}} \sum_{x_{n}} V\left(x_{n}\right) M\left(x_{n} \mid z_{T}, I_{j T}=1\right)\right] .
\end{aligned}
$$

Substituting the above into equation (50) and rearranging gives

$$
\begin{aligned}
v_{k}\left(z_{t}\right)= & u_{k t}\left(z_{t}\right)+\beta \sum_{z_{t+1}} \sum_{s=0}^{17} p_{s}\left(z_{t+1}\right)\left[u_{s t+1}\left(z_{t+1}\right)\right. \\
& \left.+E_{\varepsilon}\left(\varepsilon_{s t+1} \mid I_{s t+1}=1, z_{t+1}\right)\right] F\left(z_{t+1} \mid z_{t}, I_{k t}=1\right) \\
& +\beta^{2} \sum_{z_{t+2}} \sum_{r=0}^{17} p_{r}\left(z_{t+2}\right)\left[u_{r t+2}\left(z_{t+2}\right)+E_{\varepsilon}\left(\varepsilon_{r t+2} \mid I_{r t+2}=1, z_{t+2}\right)\right] \\
& \times \sum_{z_{t+1}} \sum_{s=0}^{17} p_{s}\left(z_{t+1}\right) F\left(z_{t+2} \mid z_{t+1}, I_{s t+1}=1\right) F\left(z_{t+1} \mid z_{t}, I_{k t}=1\right) \\
& +\beta^{3} \sum_{z_{T}} \sum_{j=0}^{17} p_{j}\left(z_{T}\right)\left[u_{j T}\left(z_{T}\right)+E_{\varepsilon}\left[\varepsilon_{j T} \mid z_{T}, I_{j T}=1\right]\right. \\
& \times \sum_{r=0}^{17} \sum_{z_{t+2}} p_{r}\left(z_{t+2}\right) F\left(z_{t+3} \mid z_{t+2}, I_{r t+2}=1\right)
\end{aligned}
$$




$$
\begin{aligned}
& \times \sum_{s=0}^{17} \sum_{z_{t+1}} p_{s}\left(z_{t+1}\right) F\left(z_{t+2} \mid z_{t+1}, I_{s t+1}=1\right) F\left(z_{t+1} \mid z_{t}, I_{k t}=1\right) \\
& +\lambda \beta^{3} \sum_{z_{T}} \sum_{j=0}^{17} p_{j}\left(z_{T}\right) N_{j}\left(z_{T}\right)^{-\nu} \\
& \times \sum_{n=1}^{N_{j}} \sum_{x_{n}} V\left(x_{n}^{\prime}\right) M\left(x_{n}^{\prime} \mid z_{T}, I_{j}=1\right) \\
& \times \sum_{z_{t+2}} \sum_{r=0}^{17} p_{r}\left(z_{t+2}\right) F\left(z_{T} \mid z_{t+2}, I_{r t+2}=1\right) \\
& \times \sum_{z_{t+1}} \sum_{s=0}^{17} p_{s}\left(z_{t+1}\right) F\left(z_{t+2} \mid z_{t+1}, I_{s t+1}=1\right) F\left(z_{t+1} \mid z_{t}, I_{k t}=1\right) .
\end{aligned}
$$

Using the definition of the optimal transition function, the above simplifies to

$$
\begin{aligned}
v_{k}\left(z_{t}\right)= & u_{k t}\left(z_{t}\right)+\beta \sum_{s=0}^{17} \sum_{z_{t+1}} p_{s}\left(z_{t+1}\right)\left[u_{s t+1}\left(z_{t+1}\right)\right. \\
& \left.+E_{\varepsilon}\left[\varepsilon_{s t+1} \mid I_{s t+1}=1, z_{t+1}\right]\right] F^{o}\left(z_{t+1} \mid z_{t}, I_{k t}=1\right) \\
& +\beta^{2} \sum_{s=0}^{17} \sum_{z_{t+2}} p_{s}\left(z_{t+2}\right)\left[u_{r s+2}\left(z_{t+2}\right)\right. \\
& \left.+E_{\varepsilon}\left[\varepsilon_{s t+2} \mid I_{s t+2}=1, z_{t+2}\right]\right] F^{o}\left(z_{t+2} \mid z_{t}, I_{k t}=1\right) \\
& +\beta^{3} \sum_{s=0}^{17} \sum_{z_{T}} p_{s}\left(z_{T}\right)\left[u_{s T}\left(z_{T}\right)+E_{\varepsilon}\left[\varepsilon_{s T} \mid z_{T}, I_{s T}=1\right]\right] F^{o}\left(z_{T} \mid z_{t}, I_{k t}=1\right) \\
& +\lambda \beta^{3} \sum_{s=0}^{17} \sum_{z_{T}} p_{s}\left(z_{T}\right) N_{s}^{-\nu}\left(z_{T}\right) \\
& \times \sum_{n=1}^{N_{s}} \sum_{x_{n}} V\left(x_{n}\right) M\left(x_{n} \mid z_{T}, I_{s T}=1\right) F^{o}\left(z_{T} \mid z_{t}, I_{k t}=1\right) .
\end{aligned}
$$

The assumption that parents are infertile in the final period of their life cycle simplifies to

$$
\begin{aligned}
v_{k}\left(z_{t}\right)= & u_{k t}\left(z_{t}\right)+\beta \sum_{s=0}^{17} \sum_{z_{t+1}} p_{s}\left(z_{t+1}\right)\left[u_{s t+1}\left(z_{t+1}\right)\right. \\
& \left.+E_{\varepsilon}\left[\varepsilon_{s t+1} \mid I_{s t+1}=1, z_{t+1}\right]\right] F^{o}\left(z_{t+1} \mid z_{t}, I_{k t}=1\right)
\end{aligned}
$$




$$
\begin{aligned}
& +\beta^{2} \sum_{s=0}^{17} \sum_{z_{t+2}} p_{s}\left(z_{t+2}\right)\left[u_{r s+2}\left(z_{t+2}\right)\right. \\
& \left.+E_{\varepsilon}\left[\varepsilon_{s t+2} \mid I_{s t+2}=1, z_{t+2}\right]\right] F^{o}\left(z_{t+2} \mid z_{t}, I_{k t}=1\right) \\
& +\beta^{3} \sum_{s=0}^{17} \sum_{z_{T}} p_{s}\left(z_{T}\right)\left[u_{s T}\left(z_{T}\right)+E_{\varepsilon}\left[\varepsilon_{s T} \mid z_{T}, I_{s T}=1\right]\right] F^{o}\left(z_{T} \mid z_{t}, I_{k t}=1\right) \\
& +\lambda \beta^{3} \sum_{z_{T}} N_{T}\left(z_{T}\right)^{-\nu} \\
& \times \sum_{n=1}^{N} \sum_{x_{n}} V\left(x_{n}\right) \sum_{s=0}^{K_{T}} M\left(x_{n} \mid z_{T}, I_{s T}=1\right) p_{s}\left(z_{T}\right) F^{o}\left(z_{T} \mid z_{t}, I_{k t}=1\right) .
\end{aligned}
$$

Proof of Proposition 2. This result follows immediately by combining the results in Proposition 1, with the replacement of the summation over $z_{t+1}$ with the integral over $z_{t+1}$.

\section{REFERENCES}

Aguirregabiria, V. (1999), "The dynamics of markups and inventories in retailing firms." Review of Economic Studies, 66 (2), 275-308. [1197]

Aguirregabiria, V. and P. Mira (2002), "Swapping the nested fixed point algorithm: A class of estimators for discrete Markov decision models.” Econometrica, 70 (4), 1519-1543. [1197, 1205, 1207, 1209, 1210]

Altuğ, S. and R. A. Miller (1998), “The effect of work experience on female wages and labour supply." Review of Economic Studies, 65 (1), 45-85. [1197, 1207, 1214, 1226]

Alvarez, F. (1999), "Social mobility: The Barro-Becker children meet the Laitner-Loury dynasties.” Review of Economic Dynamics, 2 (1), 65-103. [1196, 1198, 1203, 1204]

Arcidiacono, P. and R. A. Miller (2011), "Conditional choice probability estimation of dynamic discrete choice models with unobserved heterogeneity." Econometrica, 79 (6), 1823-1867. [1207]

Arcidiacono, P. and R. A. Miller (2015), "Nonstationary dynamic models with finite dependence." Unpublished manuscript, Department of Economics, Duke University. [1207]

Arcidiacono, P., H. Sieg, and F. Sloan (2007), "Living rationally under the volcano? An empirical analysis of heavy drinking and smoking." International Economic Review, 48 (1), 37-65. [1231]

Barro, R. J. and G. S. Becker (1988), "A reformulation of the economic theory of fertility." Quarterly Journal of Economics, 103 (1), 1-25. [1196, 1200]

Barro, R. J. and G. S. Becker (1989), "Fertility choice in a model of economic growth." Econometrica, 57 (2), 481-501. [1196, 1198, 1200] 
Becker, G. S. and H. G. Lewis (1973), "On the interaction between the quantity and quality of children." Journal of Political Economy, 81 (2, Part 2), 279-288. [1198]

Becker, G. S. and N. Tomes (1986), "Human capital and the rise and fall of families." Journal of Labor Economics, 4 (3), S1-S39. [1200]

Becker, G. S. and N. Tomes "Child endowments and the quantity and quality of children.” Journal of Political Economy, 84 (4), S143-S162. [1198]

Bernal, R. (2008), “The effect of maternal employment and child care on children's cognitive development.” International Economic Review, 49 (4), 1173-1209. [1232]

Brown, M. and C. J. Flinn (2011), "Family law effects on divorce, fertility and child investment.” Working Paper, New York University. [1232]

Caballé, J. and L. Fuster (2003), "Pay-as-you-go social security and the distribution of altruistic transfers.” Review of Economic Studies, 70 (3), 541-567. [1199]

Cagetti, M. and M. De Nardi (2008), "Wealth inequality: Data and models." Macroeconomic Dynamics, 12 (S2), 285-313. [1198]

Chamberlain, G. (1986), "Asymptotic efficiency in semiparametric models with censoring." Journal of Econometrics, 32 (2), 189-218. [1226]

De La Croix, D. and M. Doepke (2003), "Inequality and growth: Why differential fertility matters.” American Economic Review, 93 (4), 1091-1113. [1198]

De Nardi, M. (2004), "Wealth inequality and intergenerational links." Review of Economic Studies, 71 (3), 743-768. [1198]

Del Boca, D., C. Flinn, and M. Wiswall (2013), "Household choices and child development." Review of Economic Studies, 81 (1), 137-185. [1232]

Fang, H. and Y. Wang (2015), "Estimating dynamic discrete choice models with hyperbolic discounting, with an application to mammography decisions." International Economic Review, 56 (2), 565-596. [1231]

Fernández, R., N. Guner, and J. Knowles (2005), "Love and money: A theoretical and empirical analysis of household sorting and inequality." Quarterly Journal of Economics, 120 (1), 273-344. [1198]

Fuster, L., A. İmrohoroğlu, and S. İmrohoroğlu (2007), "Elimination of 'Social security in a dynastic framework." Review of Economic Studies, 74 (1), 113-145. [1199]

Galor, O. and D. N. Weil (2000), "Population, technology, and growth: From Malthusian stagnation to the demographic transition and beyond." American Economic Review, 90 (4), 806-828. [1198]

Gayle, G.-L. and L. Golan (2012), "Estimating a dynamic adverse-selection model: Labour-force experience and the changing gender earnings gap 1968-1997." Review of Economic Studies, 79 (1), 227-267. [1207, 1214, 1223, 1226] 
Gayle, G.-L., L. Golan, and M. A. Soytas (2014), "What accounts for the racial gap in time allocation and intergenerational transmission of human capital." Unpublished manuscript, Department of Economics, Washington University in St. Louis. [1196, 1199, $1200,1218,1226]$

Gayle, G.-L., L. Golan, and M. A. Soytas (2015), "What is the source of the intergenerational correlation in earnings?” Working Paper, Washington University in St. Louis. [1199]

Gayle, G.-L, L. Golan and M. Soytas (2018), "Supplement to 'Estimation of dynastic life-cycle discrete choice models.” Quantitative Economics Supplemental Material, 86, https://doi.org/10.3982/QE771. [1199, 1225, 1228]

Gayle, G.-L. and R. A. Miller (2004), "Life-cycle fertility and human capital accumulation.” Unpublished manuscript, Carnegie Mellon University. [1207, 1214, 1223]

Gayle, G.-L. and C. Viauroux (2007), "Root-n consistent semi-parametric estimators of a dynamic panel sample selection model." Journal of Econometrics, 141 (1), 179-212. [1226]

Gayle, W.-R. (2015), "CCP estimation of dynamic discrete/continuous choice models with generalized finite dependence and correlated unobserved heterogeneity." Unpublished manuscript, University of Massachusetts at Amherst. [1207, 1214]

Greenwood, J., N. Guner, and J. A. Knowles (2003), "More on marriage, fertility, and the distribution of income." International Economic Review, 44 (3), 827-862. [1228]

Greenwood, J. and A. Seshadri (2002), “The US demographic transition.” American Economic Review, 92 (2), 153-159. [1198]

Heckman, J. J., V. J. Hotz, and J. R. Walker (1985), "New evidence on the timing and spacing of births." American Economic Review, 75 (2), 179-184. [1200]

Heckman, J. J. and S. Mosso (2014), “The economics of human development and social mobility." Annual Review of Economics, 6 (1), 689-733. [1198]

Hotz, V. J. and R. A. Miller (1988), "An empirical analysis of life cycle fertility and female labor supply." Econometrica, 56 (1), 91-118. [1200]

Hotz, V. J. and R. A. Miller (1993), "Conditional choice probabilities and the estimation of dynamic models.” Review of Economic Studies, 60 (3), 497-529. [1197, 1207, 1210, 1224]

Hotz, V. J., R. A. Miller, S. Sanders, and J. Smith (1994), "A simulation estimator for dynamic models of discrete choice." Review of Economic Studies, 61 (2), 265-289. [1197, 1224]

Jones, L. E., A. Schoonbroodt, and M. Tertilt (2010), "Fertility theories: Can they explain the negative fertility-income relationship?" In Demography and the Economy, 43-100, University of Chicago Press. [1198]

Kotlikoff, L. J. and L. H. Summers (1981), “The role of intergenerational transfers in aggregate capital accumulation.” Journal of Political Economy, 89 (4), 706-732. [1199] 
Laitner, J. (1992), "Random earnings differences, lifetime liquidity constraints, and altruistic intergenerational transfers.” Journal of Economic Theory, 58 (2), 135-170. [1196] Loury, G. C. (1981), "Intergenerational transfers and the distribution of earnings." Econometrica, 49 (4), 843-867. [1196, 1200]

MaCurdy, T. E. (1981), "An empirical model of labor supply in a life-cycle setting." Journal of Political Economy, 89 (6), 1059-1085. [1226]

Magnac, T. and D. Thesmar (2002), "Identifying dynamic discrete decision processes." Econometrica, 70 (2), 801-816. [1231]

Miller, R. A. (1984), “Job matching and occupational choice." Journal of Political Economy, 92 (6), 1086-1120. [1197]

Moav, O. (2005), “Cheap children and the persistence of poverty." Economic Journal, 115 (500), 88-110. [1198]

Mookherjee, D., S. Prina, and D. Ray (2012), "A theory of occupational choice with endogenous fertility." American Economic Journal: Microeconomics, 4 (4), 1-34. [1198]

Newey, W. K. (1994), “The asymptotic variance of semiparametric estimators.” Econometrica, 62 (6), 1349-1382. [1226]

Nijman, T. and M. Verbeek (1992), "Nonresponse in panel data: The impact on estimates of a life cycle consumption function." Journal of Applied Econometrics, 7 (3), 243-257. [1226]

Pakes, A. (1986), "Patents as options: Some estimates of the value of holding European patent stocks.” Econometrica, 54 (4), 755-784. [1197]

Rios-Rull, J.-V. and V. Sanchez-Marcos (2002), “College attainment of women.” Review of Economic Dynamics, 5 (4), 965-998. [1207, 1228]

Pesendorfer, M. and P. Schmidt-Dengler (2008), "Asymptotic Least Squares Estimators for Dynamic Games.” The Review of Economic Studies, 75 (3), 901-928. [1207, 1209]

Rust, J. (1987), “Optimal replacement of GMC bus engines: An empirical model of Harold Zurcher.” Econometrica, 55 (5), 999-1033. [1197, 1210]

Wolpin, K. I. (1984), "An estimable dynamic stochastic model of fertility and child mortality." Journal of Political Economy, 92 (5), 852-874. [1197]

Zabel, J. E. (1992), "Estimating fixed and random effects models with selectivity." Economics Letters, 40 (3), 269-272. [1226]

Co-editor Peter Arcidiacono handled this manuscript.

Manuscript received 21 September, 2016; final version accepted 24 October, 2017; available online 24 January, 2018. 